\title{
CFD Extraction of Heat Transfer Coefficient in Cryogenic Propellant Tanks
}

\author{
H. Q. Yang. ${ }^{1}$ \\ CFD Research Corp., Jacob ESSSA Group, NASA MSFC \\ Huntsville, AL 35806 \\ and \\ Jeff West $t^{2}$ \\ NASA MSFC
}

\begin{abstract}
Current reduced-order thermal model for cryogenic propellant tanks is based on correlations built for flat plates collected in the 1950's. The use of these correlations suffers from inaccurate geometry representation; inaccurate gravity orientation; ambiguous length scale; and lack of detailed validation. This study uses first-principles based CFD methodology to compute heat transfer from the tank wall to the cryogenic fluids and extracts and correlates the equivalent heat transfer coefficient to support reduced-order thermal model. The CFD tool was first validated against available experimental data and commonly used correlations for natural convection along a vertically heated wall. Good agreements between the present prediction and experimental data have been found for flows in laminar as well turbulent regimes. The convective heat transfer between the tank wall and cryogenic propellant, and that between the tank wall and ullage gas were then simulated. The results showed that the commonly used heat transfer correlations for either vertical or horizontal plate over-predict heat transfer rate for the cryogenic tank, in some cases by as much as one order of magnitude. A characteristic length scale has been defined that can correlate all heat transfer coefficients for different fill levels into a single curve. This curve can be used for the reduced-order heat transfer model analysis.
\end{abstract}

\section{Nomenclature}

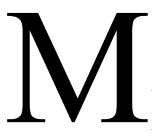
odeling propellant tank dynamics including slosh, pressurization, propellant conditions, and thermodynamics of heat and mass transfer across gas-liquid interface for liquid propellant based space vehicles is very important. In the development of Saturn stages, such as S-IC, S-II, S-IVB, in the 1960s, the analyses were done typically using reduced thermal models $[1,2]$. With the advancement of Computational Fluid Dynamics (CFD) technology, it is possible to model the propellant tank dynamics from a first-principles based approach. The reduced thermal models [1-4] have the advantage of fast turnaround time for parametric studies and are easy to use. Recently, an improved analytical thermal modeling for propellant tank has been developed at NASA MSFC [4]. The model validation has been proven successful against previous models [3] and various Saturn era test data and reasonably successful against more recent LH2 tank self-pressurization ground test data.

${ }^{1}$ Chief Scientist, CFD Research Corp., 701 McMillian Way, Huntsville, AL 35806, AIAA Senior Member

${ }^{2}$ Team Lead, Fluid Dynamics Branch-ER42, George C. Marshall Space Flight Center, AL 35812, AIAA Member 
The reduced thermal models for cryogenic tanks [2,4] typically divide the propellant tank into nodes and implement an empirical correlation for heat transfer between different nodes. For example in the model of Reference [4], fives nodes are used as shown in Figure 1, with a tank wall node exposed to ullage gas, an ullage gas node, a saturated propellant vapor node at the liquid-vapor interface, a liquid node, and a tank wall node exposed to liquid. The conservation equations for mass and energy are then applied across all the node boundaries and, with the use of perfect gas assumptions, explicit solutions for ullage and liquid conditions are derived.

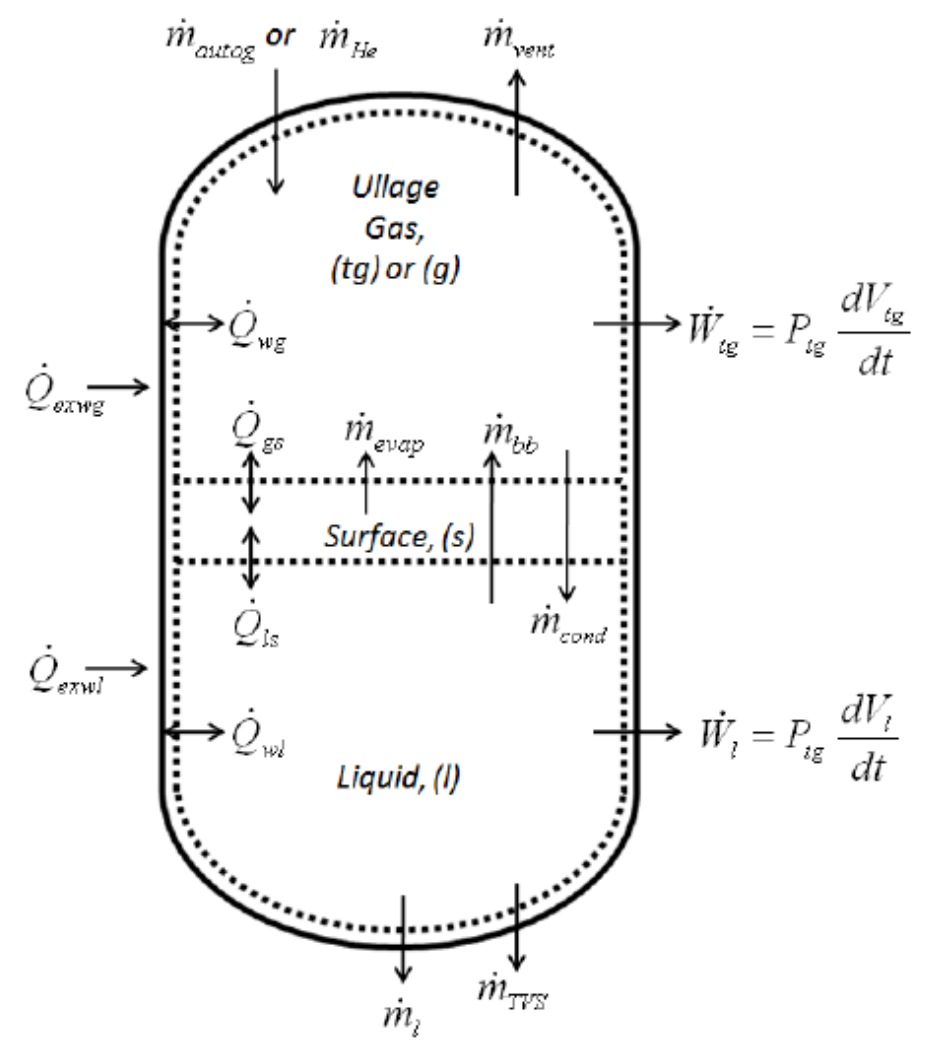

Figure 1: Diagram of control volume for the analytical thermal model [4].

From a fluid physics point of view, the heat transfer between the tank wall node exposed to the ullage gas and the ullage gas node, and that between the liquid node and the tank wall node exposed to the liquid, are all by natural convection which involves complex fluid dynamics. In the reduced thermal model, the calculation of heat and mass transfer between the cryogenic propellant tank wall and the internal fluids was based on correlation dependencies created from experimental data. Some of these correlations were built long ago [2] (condensation on the vertical wall - 1960) and some more recently; but some of them still need to be constructed. One of the most important parameters is the correlation for heat transfer from the tank dome to the ullage gas and from the tank wall to the liquid (see Fig. 1). At the present time, calculations are made by converting spherical or elliptical domes to equivalent flat plates and using correlations for the flat plates. Even so, for the upper domes or for the downwardfacing plates, the correlations don't account for the presence of a cylindrical barrel section, which must be considered in practical design. New correlations are still required to properly account for the heat transfer between the tank wall and the propellants inside the tank from which a reliably reduced model can be formulated.

The application of existing correlations developed from flat plates to cryogenic tanks suffers from:

- Inaccurate geometry representation (spherical and cylindrical surfaces are approximated by a flat surface);

- Inaccurate gravity orientation (an inclined surface is approximated as either a vertical or a horizontal surface);

- Ambiguous length scale (tank diameter, barrel height, or tank height);

- Ambiguous computation domain as the correlated heat transfer coefficients are constructed for a flat surface in an infinite medium, whereas the application is for the finite space inside a tank; and 
- Lack of detailed validation (the temperature field inside fluid is stratified rather than uniform as assumed in the reduced-order model, and validation must be made with respect to volume averaged temperature which is difficult to obtain from experiment)

The objective of this study is to use a first-principles based CFD technique to compute heat transfer from the tank wall to the cryogenic fluids, and extract and correlate the equivalent heat transfer coefficient to support reduced-order thermal model development. There are many advantages of the current approach:

- ability to use the exact tank geometry;

- a validated CFD model;

- physics based length scale; and

- a heat transfer data extraction procedure that is consistent with the reduced-order thermal model to ensure energy conservation.

\section{Computational Fluid Dynamics (CFD) Solution}

The basic CFD software used to study the heat transfer inside the cryogenic tank is the commercial code, CFD$\mathrm{ACE}+$, which was originally developed by CFD Research Corp., and is currently owned and distributed by ESI Group USA. CFD-ACE+ solves conservation of mass, momentum (Navier-Stokes equations) and energy. The mass and momentum continuity equations can be generally written as:

$$
\begin{gathered}
\frac{\partial \rho}{\partial t}+\nabla \bullet(\rho \vec{V})=0 \\
\frac{\partial(\rho u)}{\partial t}+\nabla \bullet(\rho \vec{V} u)=\frac{\partial\left(-p+\tau_{x x}\right)}{\partial x}+\frac{\partial \tau_{y x}}{\partial y}+\frac{\partial \tau_{z x}}{\partial z}+S_{M x}, \\
\frac{\partial(\rho v)}{\partial t}+\nabla \bullet(\rho \vec{V} v)=\frac{\partial \tau_{x y}}{\partial x}+\frac{\partial\left(-p+\tau_{y y}\right)}{\partial y}+\frac{\partial \tau_{z y}}{\partial z}+S_{M y}, \\
\frac{\partial(\rho w)}{\partial t}+\nabla \bullet(\rho \vec{V} w)=\frac{\partial \tau_{x z}}{\partial x}+\frac{\partial \tau_{y z}}{\partial y}+\frac{\partial\left(-p+\tau_{z z}\right)}{\partial z}+S_{M z}
\end{gathered}
$$

where $\rho$ is the density, $\mathrm{u}, \mathrm{v}$, and $\mathrm{w}$ are the velocity components in $\mathrm{x}, \mathrm{y}$, and $\mathrm{z}$ directions. $\mathrm{V}$ is the velocity vector, $\mathrm{p}$ the static pressure, $t$ the time, and $\mathrm{S}_{\mathrm{Mx}}, \mathrm{S}_{\mathrm{My}}$ and $\mathrm{S}_{\mathrm{Mz}}$ are the momentum source in $\mathrm{x}, \mathrm{y}$, and $\mathrm{z}$ directions, respectively.

For Newtonian flows, the viscous stresses $\left(\tau_{\mathrm{ij}}\right)$ are proportional to the deformation rates of the fluid element. The nine viscous stress components can be related to velocity gradients to produce the following shear stress terms:

$$
\begin{gathered}
\tau_{x x}=2 \mu \frac{\partial u}{\partial x}-\frac{2}{3} \mu(\nabla \bullet \vec{V}) \\
\tau_{y y}=2 \mu \frac{\partial v}{\partial y}-\frac{2}{3} \mu(\nabla \bullet \vec{V}) \\
\tau_{y y}=2 \mu \frac{\partial w}{\partial z}-\frac{2}{3} \mu(\nabla \bullet \vec{V}) \\
\tau_{x y}=\tau_{y x}=\mu\left(\frac{\partial u}{\partial y}+\frac{\partial v}{\partial x}\right) \\
\tau_{x z}=\tau_{z x}=\mu\left(\frac{\partial u}{\partial z}+\frac{\partial w}{\partial x}\right) \\
\tau_{y z}=\tau_{z y}=\mu\left(\frac{\partial v}{\partial z}+\frac{\partial w}{\partial y}\right) .
\end{gathered}
$$


For the natural convection problem under this study, the momentum source includes the buoyancy force applied through the Boussinesq approximation.

For heat transfer problems, CFD-ACE + solves the total enthalpy equation derived from energy conservation:

$$
\begin{aligned}
\frac{\partial \rho h_{o}}{\partial t}+\nabla \bullet\left(\rho \vec{V} h_{o}\right)=\nabla \bullet\left(K_{e f f} \nabla T\right)+\frac{\partial p}{\partial t}+\left[\frac{\partial\left(u \tau_{x z}\right)}{\partial x}+\right. & \left.\frac{\partial\left(u \tau_{y x}\right)}{\partial y}+\frac{\partial\left(u \tau_{z x}\right)}{\partial z}\right]+\left[\frac{\partial\left(v \tau_{x y}\right)}{\partial x}+\frac{\partial\left(v \tau_{y y}\right)}{\partial y}+\frac{\partial\left(v \tau_{y z}\right)}{\partial z}\right] \\
& +\left[\frac{\partial\left(w \tau_{x z}\right)}{\partial x}+\frac{\partial\left(w \tau_{y z}\right)}{\partial y}+\frac{\partial\left(w \tau_{z z}\right)}{\partial z}\right]+S_{h}
\end{aligned}
$$

where $h_{0}$ is the total enthalpy and is defined as:

$$
h_{o}=i+\frac{p}{\rho}+\frac{1}{2}\left(u^{2}+v^{2}+w^{2}\right),
$$

where $i$ is the internal energy and is a function of the state variables of density $\rho$ and temperature $T$. $K_{\text {eff }}$ is the effective thermal conductivity of the material. In laminar flow, $\mathrm{K}_{\text {eff }}$ is the thermal conductivity of the fluid, $\mathrm{K}$. In turbulent flows:

$$
K_{\text {eff }}=K+\frac{\mu_{t} C_{p}}{\sigma_{t}},
$$

with $\mu_{t}$ being the turbulent viscosity and $\sigma_{t}$ the turbulent Prandtl number.

The most relevant fluid dynamics features of CFD-ACE+ are:

- Pressure-based, strongly implicit algorithm solving Navier-Stokes equations for all flow speeds;

- High order TVD scheme and high order time-stepping for high spatial and temporal resolution;

- Unstructured, mixed element grids for complex geometrical problems, including tetra-, hexa-, adaptive Cartesians, pyramids, prisms, polyhedral and cells with multiple hanging nodes;

- Co-located (non-staggered) grid topology;

- A space-conserving moving grid formulation that allows the treatment of moving-deforming grid systems;

- Comprehensive set of boundary conditions;

- Stationary, deforming, moving, rotating frame of reference;

- Various turbulence models for Reynolds Averaged Navier-Stokes Equation, including:

- Standard $k$ - $\varepsilon$ Model of Launder and Spalding [5]

- RNG $k-\varepsilon$ Model

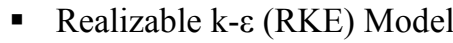

- Kato-Launder $k$ - $\varepsilon$ Model

- Low Reynolds Number k-e Model (Chien)

- Two-Layer $k$ - $\varepsilon$ Model of Chen \& Patel [6]

- $k$ - $\omega$ Model

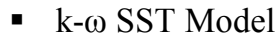

- Spalart-Allmaras Model

- Various subgrid-scale stress models for Large Eddy Simulations

- Smagorinsky SGS model

- Germano's Dynamic Subgrid-Scaled model

- Menon's Localized Dynamic Subgrid-Scale Model

\section{Validation Study of Natural Convection over a Vertical Plate}

Before we apply CFD technology to the cryogenic tank heat transfer problem, it is very important to make a systematic validation study. As the empirical correlation of heat transfer coefficient for the flat plate has been widely used in the reduced thermal model, it is crucial to verify that CFD can reproduce the classical experimental data. The first task here is to perform validation for natural convection along a vertical plate in both laminar and turbulent regimes with air as the working medium. 


\section{A. Validation Model and Fluid Physics}

Figure 2 shows the fluid dynamics process of natural convection along a vertical plate. Here a fluid medium is subjected to a warm wall temperature. The warm wall heats the near-wall fluid. Near-wall fluid flows in $+x$ direction due to buoyancy effects. As the fluid flows along the wall, it draws in more heat ( $\mathrm{T}$ is a function of $\mathrm{y}$ ). Thermal boundary layer forms and grows thicker because of local heat transfer q"(x). More fluid is drawn in from the fluid medium, and the process continues.

There are several important non-dimensional parameters for the natural convection problem.

a. Prandtl Number. Prandtl number is the ratio of viscous diffusivity, $v$, to thermal diffusivity, $\alpha$, and is defined as:

$$
\operatorname{Pr}=\frac{v}{\alpha} .
$$

b. Rayleigh Number. Rayleigh number is the ratio of buoyant forces to viscous forces multiplied by the ratio of viscous diffusivity to thermal diffusivity. Rayleigh number is defined as:

$$
R a=\frac{g \beta \Delta T L^{3}}{v \alpha},
$$

where $\mathrm{L}$ is the characteristic length, $\beta$ is the thermal expansion coefficient, and $\Delta \mathrm{T}$ is the temperature difference.

c. Local Nusselt number. Local Nusselt number is the ratio of convective to conductive heat transfer. The typical formulation for Nusselt number is $\mathrm{Nu}=\mathrm{f}(\mathrm{Pr}, \mathrm{Ra})$. Nusselt number is given by:

$$
N u=\frac{h x}{K} .
$$

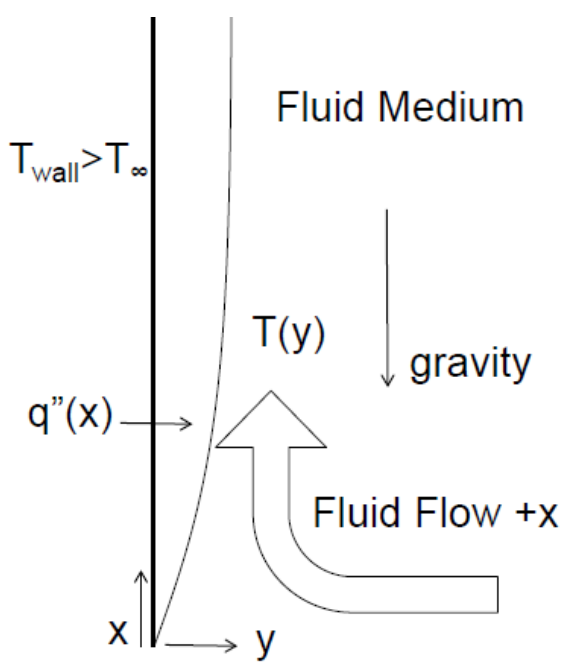

Figure 2: Fluid physics of natural convection over a vertical flat plate.

\section{B. Previous Experimental Data and Empirical Correlations}

For natural convection over a vertical flat plate, several experiment-derived datasets exist correlating the nondimensional Nusselt number as a function of $\mathrm{Ra}$ as shown in Figure 3. During the early development of an analytical similarity solution for natural convection along a vertical plate, these data were used to validate the asymptotic analytical solution [7]. For example, the boundary layer similarity solution gives $1 / 4$ power law for laminar flow, and 1/3 power law for turbulent flow, as seen in Figure 3. These empirical correlations have been widely used in the reduced thermal model analysis for cryogenic tank thermal analysis $[2,4]$. The general form of the averaged natural convection expression is:

$$
\overline{N u}=C(R a)^{n}
$$


Based on the orientation of the flat plate to the gravity vector, and Ra number, $\mathrm{C}$, and $\mathrm{n}$ take on different values.

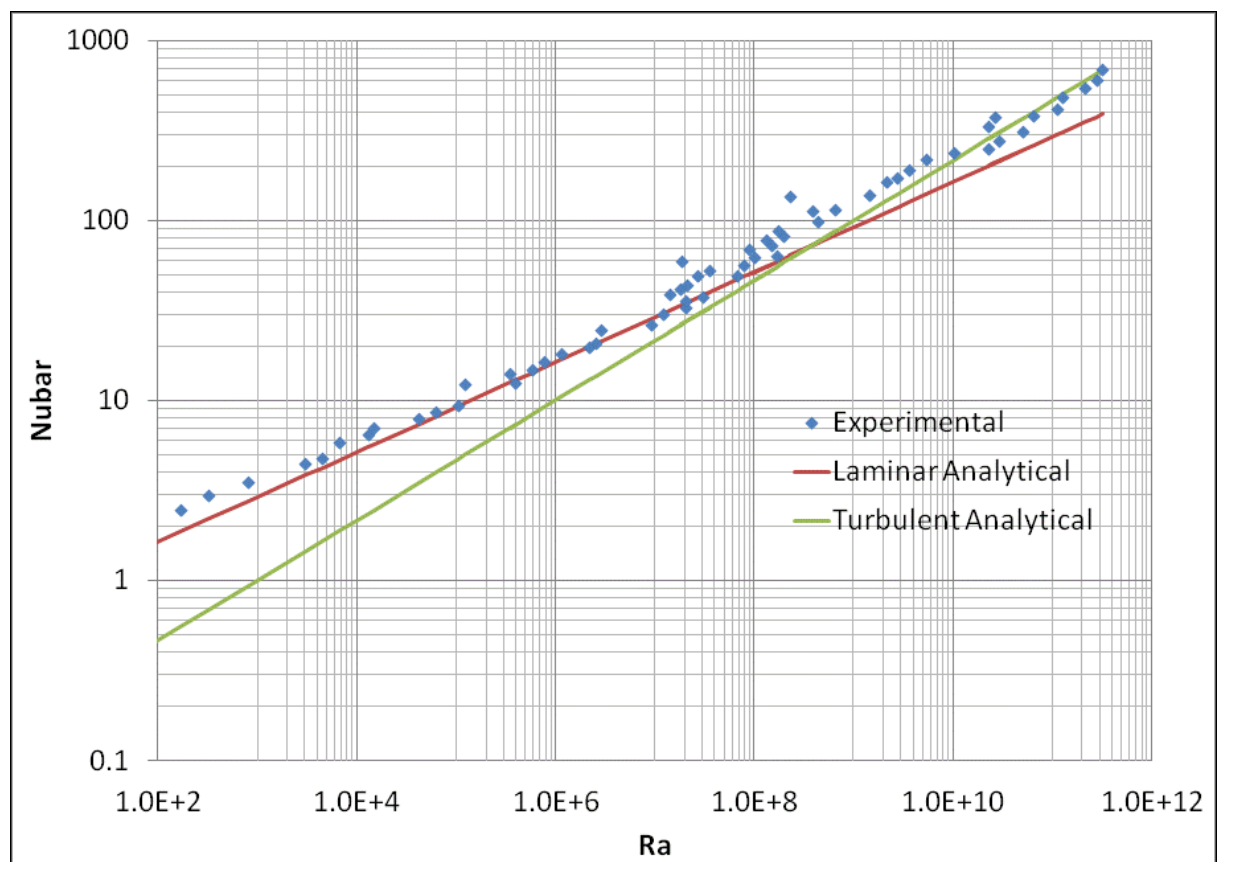

Figure 3: Experimental data and empirical correlations for natural convection over a vertical flat plate from surveyed literature [7].

\section{Experimental Data Correlations}

For the vertical surfaces:

For Laminar Range: $10^{4}<\mathrm{Ra}<10^{9} ; \quad \mathrm{C}=0.59, \mathrm{n}=1 / 4$.

For turbulent Range: $10^{9}<\mathrm{Ra}<10^{13} ; \mathrm{C}=0.13, \mathrm{n}=1 / 3$.

For the horizontal surfaces: above hotter surface, below cooler surfaces

For Laminar Range: $\quad 10^{5}<\mathrm{Ra}<2 \times 10^{7} ; \mathrm{C}=0.54, \mathrm{n}=1 / 4$

For turbulent Range: $2 \times 10^{7}<\mathrm{Ra}<3 \times 10^{10} ; \mathrm{C}=0.14, \mathrm{n}=1 / 3$

For the horizontal surfaces: below hotter surface, above cooler surfaces

For Laminar Range: $3 \times 10^{5}<\mathrm{Ra}<3 \times 10^{10} ; \mathrm{C}=0.27, \mathrm{n}=1 / 4$

No correlation in the turbulent regime.

The above experimental data correlations will be used for the present validation study.

\section{CFD Model and Boundary Conditions}

The CFD simulation domain is shown in Figure 4. As the experimental data were collected in an infinite medium, the size of the domain is selected such that the far field boundary condition has limited impact on the results. A 2D model was built with an assumption that the plate is wide enough such that the edge effect can be neglected. The flat plate itself is assumed to be infinitely thin so that only half of the domain needs to be considered. The condition on the flat plate is a constant temperature and non-slip velocity. Below the plate, it has a vertical symmetry condition. At far field down below the plate, the pressure is constant, and the temperature is the freestream value. On the right-hand side of the domain, a symmetry condition is imposed. 


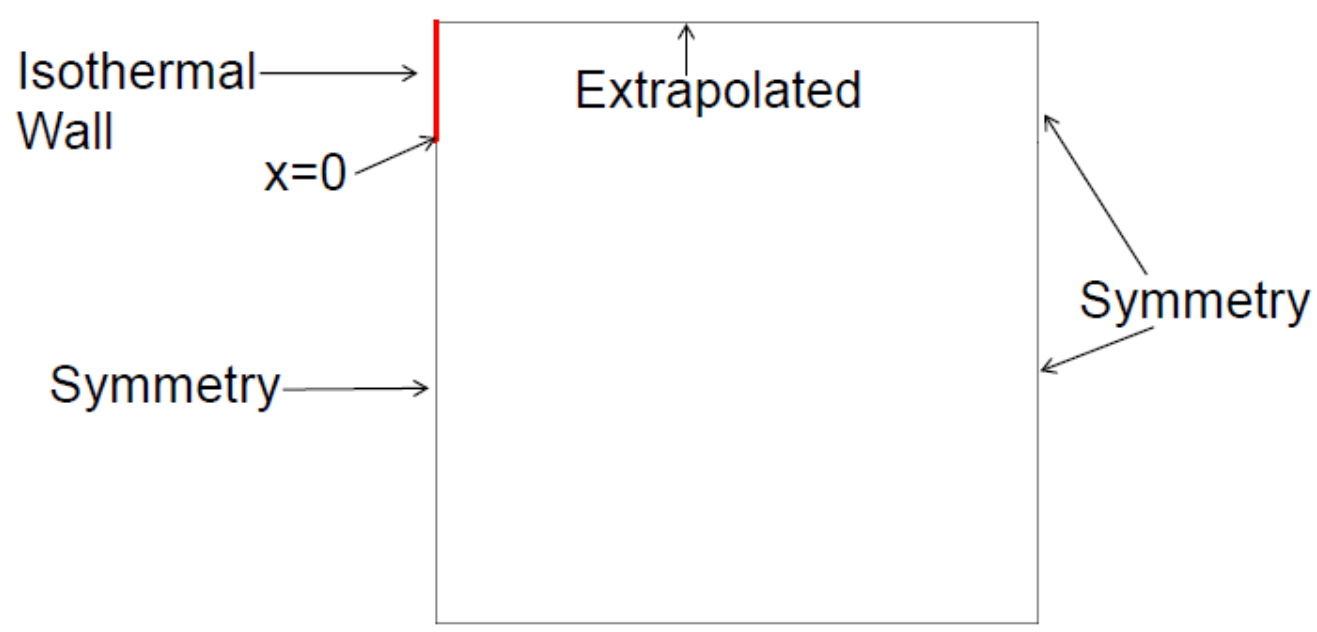

\section{Fixed Pressure}

Figure 4: CFD simulation model for heat transfer over a vertical flat plate.

The computational grid is shown in Figure 5, where the mesh is packed near the plate. There is a total of 90k cells in the baseline grid.

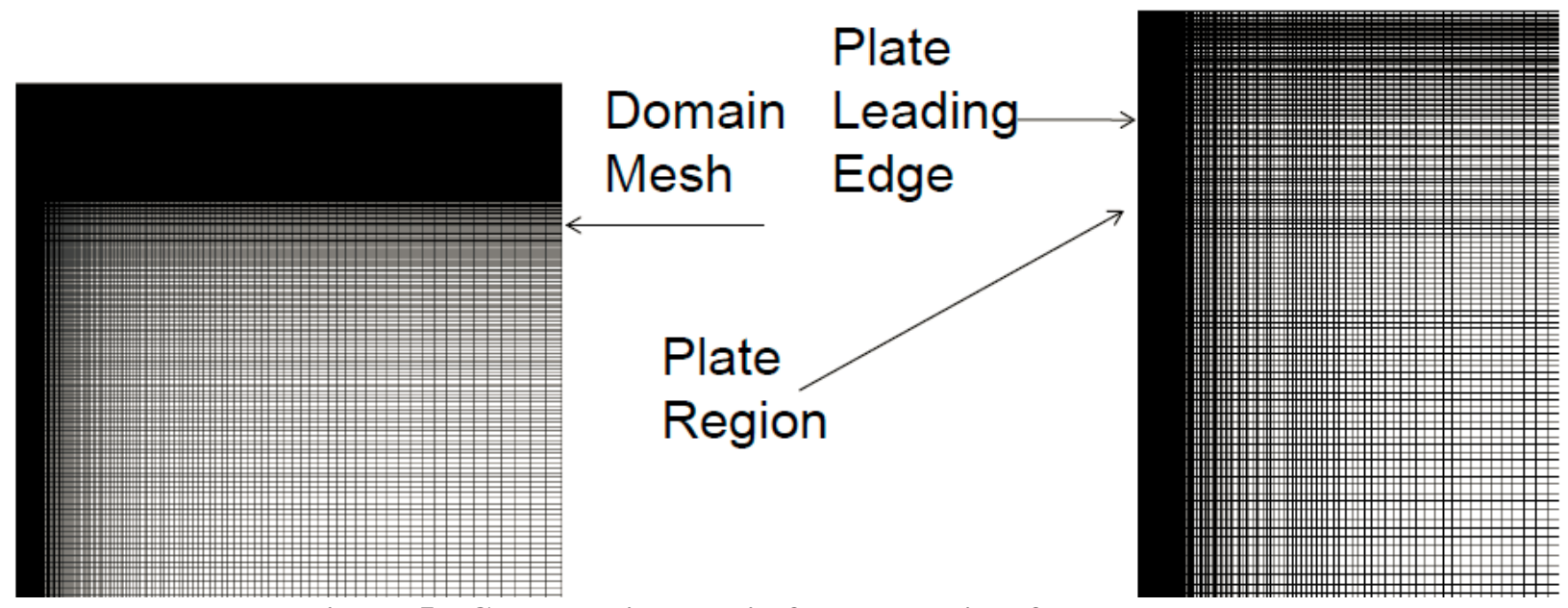

Figure 5: Computational grid for the vertical flat plate model.

\section{Validation for Laminar Regime}

For the validation studies of laminar flow over a flat plate, we consider Ra number up to $10^{6}$. From the equation (10), one can see that Rayleigh number is a function of gravity acceleration g. Under the same thermal conditions, different gravity levels can give different Rayleigh numbers. By changing gravity input, one can change the Rayleigh number. For air, the properties are given in Table 1 under ambient temperature of $\mathrm{T}=300^{\circ} \mathrm{K}$ and ambient pressure of $\mathrm{P}=1.0 \times 10^{5} \mathrm{~N} / \mathrm{m}^{2}$.

Table 1. Air Properties Used in the Validation Study.

\begin{tabular}{|c|c|}
\hline Property & Value \\
\hline Density, $\rho(\mathrm{kg} / \mathrm{m} 3)$ & 1.225 \\
\hline Viscosity, $\mu\left(\mathrm{kg} / \mathrm{m}^{*} \mathrm{~s}\right)$ & $1.79 \mathrm{E}-5$ \\
\hline Specific Heat, $\mathrm{Cp}\left(\mathrm{J} / \mathrm{kg}{ }^{*} \mathrm{~K}\right)$ & 1005 \\
\hline Thermal Conductivity, $\mathrm{K}\left(\mathrm{W} / \mathrm{m}^{*} \mathrm{~K}\right)$ & .0257 \\
\hline Thermal Expansion Coefficient, $\beta(1 / \mathrm{K})$ & .00343 \\
\hline
\end{tabular}


To extract the area averaged heat transfer rate, the local heat flux into the wall is first calculated as:

$$
q^{\prime \prime}\left(x^{\prime}\right)=K_{f} \frac{\partial T}{\partial y}
$$

The mean heat flux up to the point $\mathrm{x}$ is the result of averaging the above heat flux:

$$
\bar{q}^{\prime \prime}(x)=\frac{\int_{0}^{x} q^{\prime \prime}\left(x^{\prime}\right) d x^{\prime}}{x}
$$

Based on the mean heat flux, one can compute the mean Nusselt number as:

$$
\overline{N u}(x)=\frac{\bar{q}^{\prime \prime}}{\left(T_{w}-T_{\infty}\right)} \frac{x}{K_{f}}
$$

The length scale in the Rayleigh number is based on the above $\mathrm{x}$.

Given in Figure 6 is the local heat transfer computed using equation (14) after the CFD solution has reached steady state. Both $1^{\text {st }}$ and $2^{\text {nd }}$ spatial schemes are applied. Near the leading edge of the plate, the boundary layer is very thin which gives rise to a locally high heat flux. After the leading edge, the heat flux is nearly uniform.

By integrating the surface heat flux value as the above equation (14) and using the definition of (15), the present CFD simulation of heat transfer rate in terms of Nusselt number as a function of Rayleigh number is given in Figure 7. The experimental data and empirical correlation based on thermal boundary layer solution [7] is also shown in the same figure for this laminar flow regime. One can see that from $\mathrm{Ra}=10^{4}$ and up, all three agree with each other very well in term of heat transfer value. Also, all three show the same trend, $1 / 4$ power of Rayleigh number. This implies the laminar boundary layer as the dominant heat transfer mechanism. When Rayleigh number is below $10^{4}$, one starts to see the deviation of empirical correlation relative to the experimental data and the present CFD simulation. It is expected that at low Rayleigh number, the heat transfer mechanism is conduction dominated, and Nusselt number should approach a constant. That is indeed what experimental measurements and the CFD predictions show. In terms of the present CFD simulation, one can see fair good agreement with experimental data even down to Rayleigh number order of 1 .

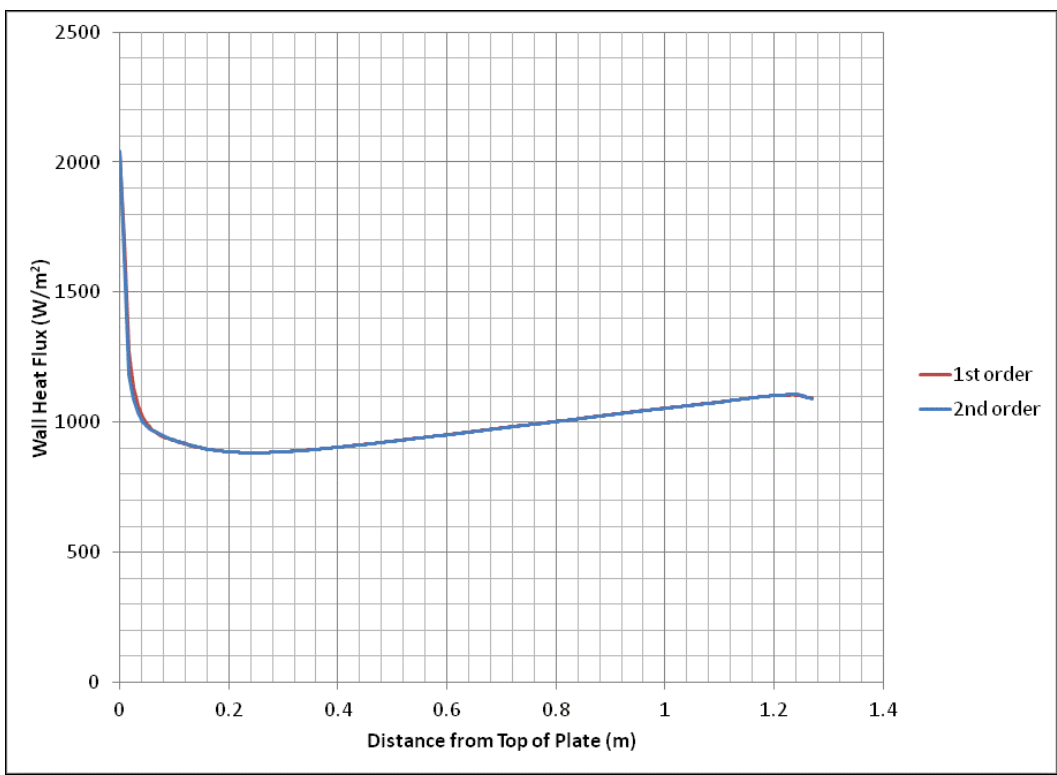

Figure 6: Local heat flux from the present simulation using different differencing schemes. 


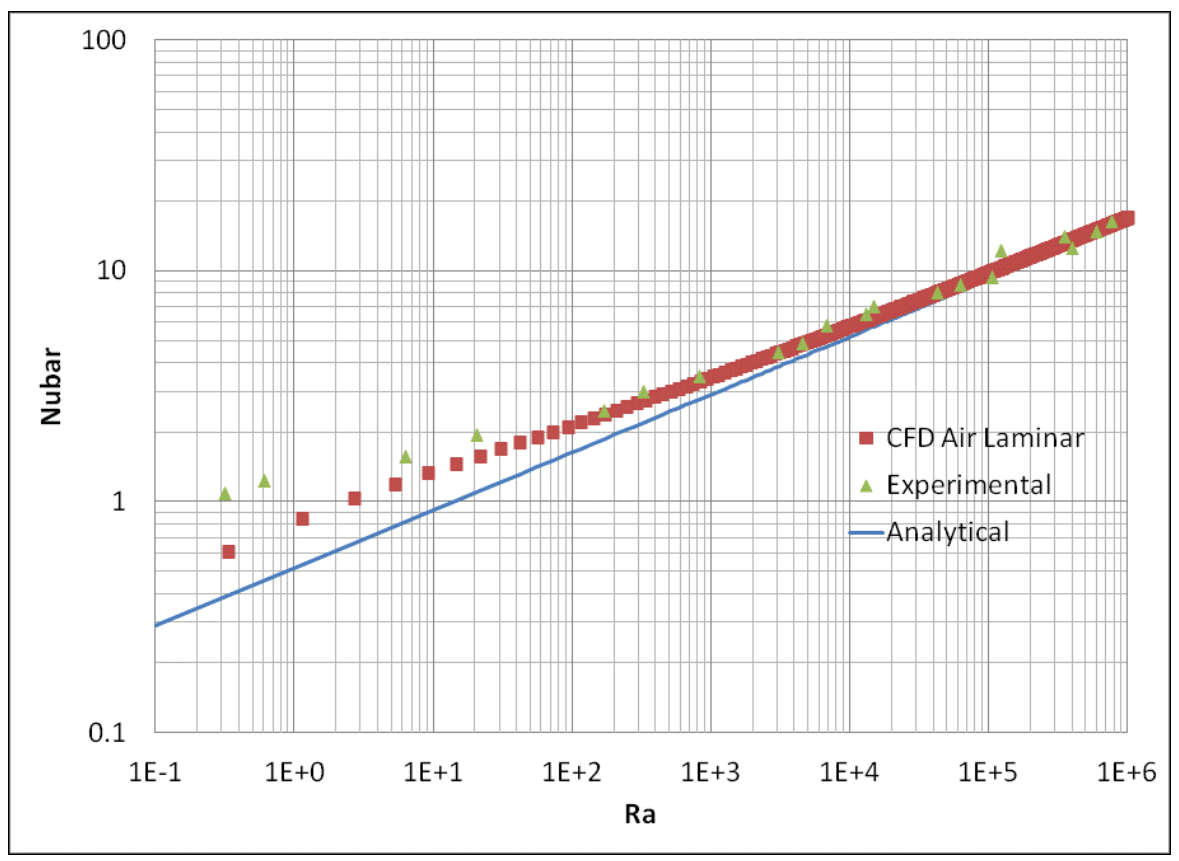

Figure 7: Comparison of mean Nusselt number from the present CFD prediction, experimental data, and empirical correlations.

To ensure the solution is mesh-independent, the simulations are made with additional two finer meshes of $120 \mathrm{k}$ and 240k. The results are displayed in Figure 8. It is clear that the present baseline 90k cell gives a grid-independent solution.

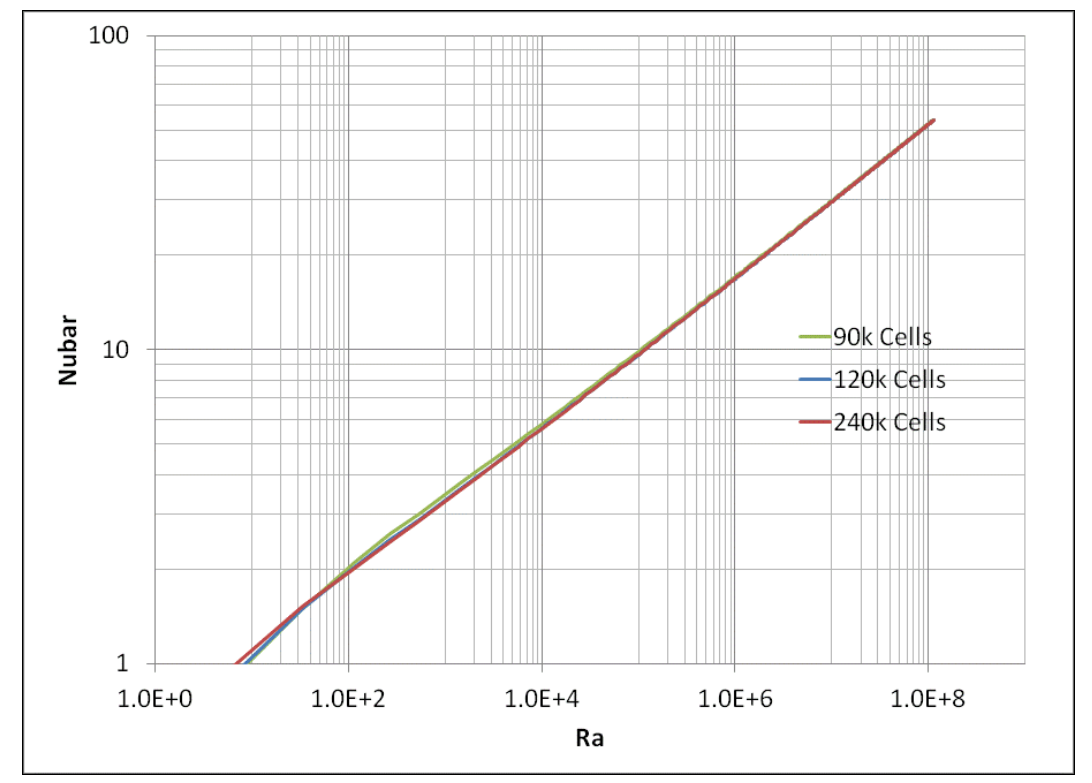

Figure 8: Mesh independent study for laminar natural convection over a vertical flat plate.

\section{E. Validation for Turbulent Regime}

When Rayleigh is above $10^{9}$, flow is turbulent. To model the enhanced heat transfer due to turbulence, one can use one of many turbulence models in CFD-ACE+. The following four turbulence models have been assessed against experimental data:

- Standard k- $\varepsilon$ model of Launder and Spalding [5];

- K- $\omega$ model; 
- $\quad$ STT model, which blends k- $\varepsilon$ near wall and $\mathrm{k}-\omega$ away from the wall;

- two layer k- $\varepsilon$ model of Chen \& Patel [6], which blends high Reynolds number and low Reynolds number model.

The results are shown in Figure 9. It can be concluded that:

- $\quad \mathrm{k}-\varepsilon$ model diverges from all other models and experimental data at high Ra;

- $\quad$ SST model is highly over-predictive at low Rayleigh number;

- two layer $k-\varepsilon$ and $k-\omega$ models are very competitive.

Based on the above observations, it was decided that the two-layer k- $\varepsilon$ model will be used for the subsequent simulations, as the model is designed for resolving viscous and thermal boundary layers without using wall functions. Another feature of two layer k- $\varepsilon$ is that it can resolve the effect of surface curvature and flow separation, which could occur for cryogenic tank problems.

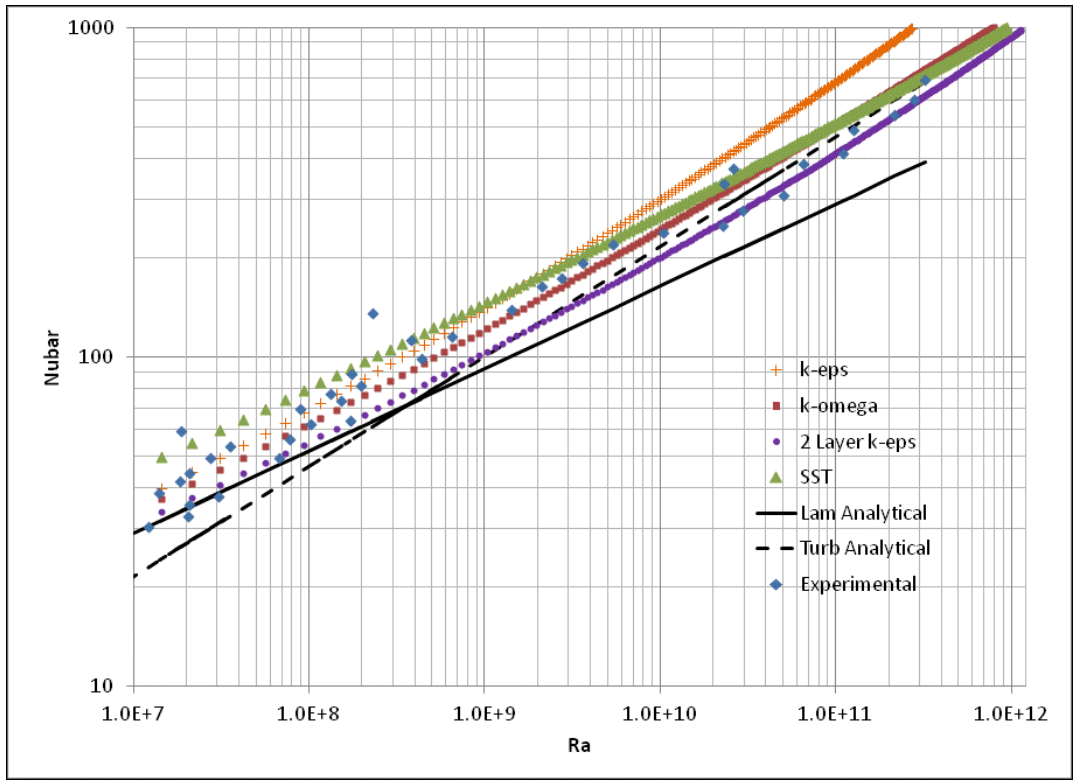

Figure 9: Evaluation of turbulence models for natural convection over a vertical flat plate.

Figure 10 shows the comparison of heat transfer in the turbulent flow regime using the two layer k- $\varepsilon$ model, along with the experimental data and empirical correlations. One observes that the CFD simulations match very well with the experimental data from low Rayleigh number of $\mathrm{Ra}=10^{4}$ up to high Rayleigh number of $\mathrm{Ra}=10^{11}$. The empirical correlation of heat transfer with a $1 / 3$ power to $\mathrm{Ra}$ in high Rayleigh number regime and $1 / 4$ power to $\mathrm{Ra}$ in lower Rayleigh number regime are all displayed from the simulation results. There is some scatter in the experimental data in the transition regime, but all the essential physics of heat transfer are well represented in the present numerical study. This builds a sound foundation for the heat transfer study inside cryogenic tanks. 


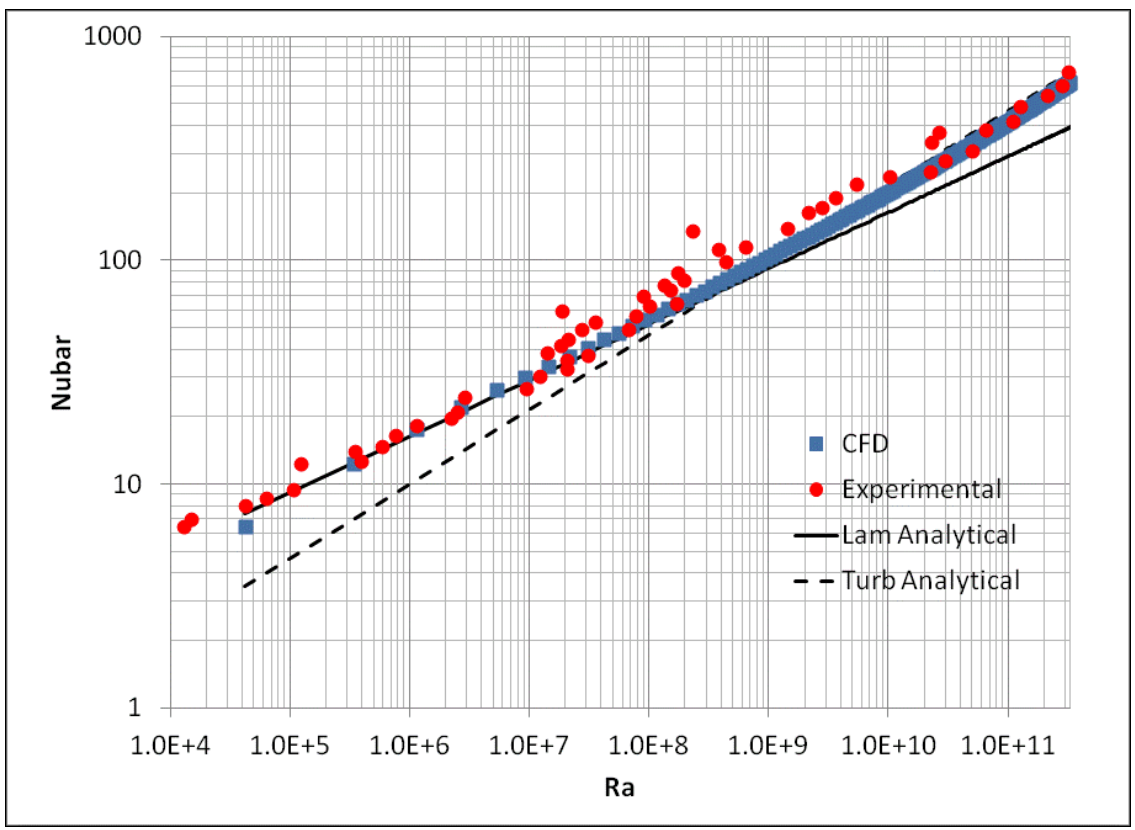

Figure 10: Validation of two layer $k-\varepsilon$ model for natural convection over a vertical plate.

Figure 11 shows the mesh-independence study for turbulence simulation. Indeed solutions for different meshes show little or no difference, and mesh independence is achieved at the 90,000 cell level.

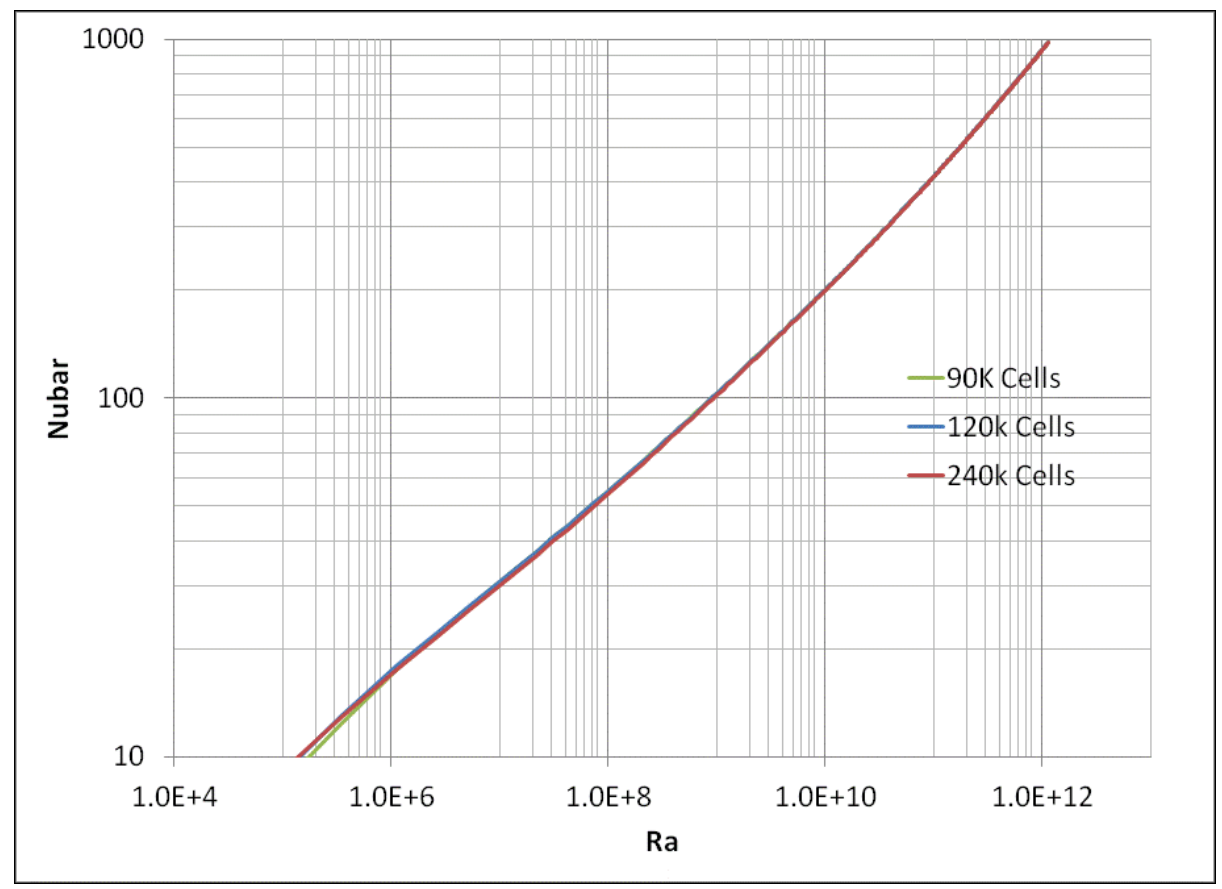

Figure 11: Heat transfer sensitivity to grid mesh sizes for the two-layer k- $\varepsilon$ model.

\section{CFD Extraction of Heat Transfer Coefficient}

Analysis of heat transfer inside cryogenic tanks is crucial for the design of space launch vehicles. There is, however, a lack of such experimental heat transfer data available for cryogenic tanks. Our current approach is to use a validated CFD tool to predict and to correlate the natural convection heat transfer between the liquid phase and 
the tank wall, and between gas phase and the tank wall. The successful validation exercise outlined in the previous sections provides a sound foundation for such predictions.

\section{A. Technical Approach for Heat Transfer in Cryogenic Tank}

The general approach is to partition the tank into several sub-models, and use CFD to extract the heat transfer coefficient for each sub-model. The extracted heat transfer coefficient will then be employed in a reduced thermal model analysis.

Before extracting the heat transfer coefficient, it is important to review the reduced thermal model used in the cryogenic tank analysis $[2,4]$. The typical reduced thermal model divides the tank into 5 nodes as shown in Figure 11.

1. TWG: Tank wall node exposed to ullage gas;

2. $\mathrm{T}_{\mathrm{G}}$ : Ullage gas node;

3. $\mathrm{T}_{\mathrm{GL}}$ : Saturated propellant vapor node at liquid-vapor interface;

4. $\mathrm{T}_{\mathrm{L}}$ : Liquid node; and

5. $\mathrm{T}_{\mathrm{wL}}$ : Tank wall node exposed to liquid.

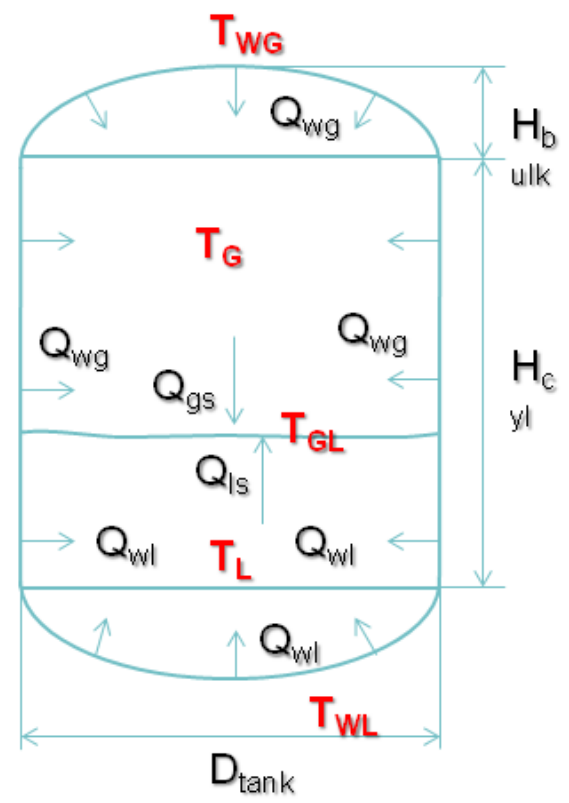

Figure 12: Reduced thermal model for cryogenic tank.

The energy conservation equation for the ullage gas node (assuming no mass transfer) can be written as:

$$
\frac{\partial\left(\rho_{G} c_{p G} T_{G}\right)}{\partial t}=Q_{w g}-Q_{g s},
$$

where $\mathrm{Q}_{\mathrm{wg}}$ is the heat flux from the tank wall to the ullage, and $\mathrm{Q}_{\mathrm{gs}}$ is the heat flux from the ullage to gas-liquid interface. And $\mathrm{Q}_{\mathrm{wg}}$ and $\mathrm{Q}_{\mathrm{gs}}$ are given by:

$$
\begin{gathered}
Q_{w g}=h_{w g} A_{w g} \Delta T, \\
Q_{g s}=h_{g s} A_{g s} \Delta T .
\end{gathered}
$$

The energy conservation for the liquid node is

$$
\frac{\partial\left(\rho_{L} c_{p L} T_{L}\right)}{\partial t}=Q_{w l}-Q_{l s}
$$


where $\mathrm{Q}_{\mathrm{wl}}$ is the heat flux from the tank wall to liquid, and $\mathrm{Q}_{\mathrm{ss}}$ is the heat flux from liquid to gas-liquid interface. And $\mathrm{Q}_{\mathrm{wl}}$ and $\mathrm{Ql}_{\mathrm{s}}$ are given by:

$$
\begin{aligned}
& Q_{w l}=h_{w l} A_{w l} \Delta T, \\
& Q_{l s}=h_{l s} A_{l s} \Delta T .
\end{aligned}
$$

Our goal is to determine the heat transfer coefficients of $h_{w g}, h_{g s}, h_{w l}$, and $h_{l s}$.

\section{B. Extraction of Heat Transfer Rate by Steady State Simulation}

Our experience indicated that the extraction of a converged heat transfer coefficient from a transient simulation is difficult, and a meaningful extraction of heat transfer rate between tank walls and the internal fluids is by a steadystate approach. A steady-state solution to heat transfer problem requires a heat source and a heat sink. In the current cryogenic tank problem, the tank wall can be taken as a heat source. The question is where the heat sink is located. It is noted that as the liquid phase has a much higher heat capacity, and the gas-liquid interface is maintained at the saturated temperature, it is reasonable to assume that gas-liquid interface behaves as the heat sink as illustrated in Figure 13. With high and low temperatures specified, the ullage gas is the media between the tank wall and gasliquid interface to convect the heat.

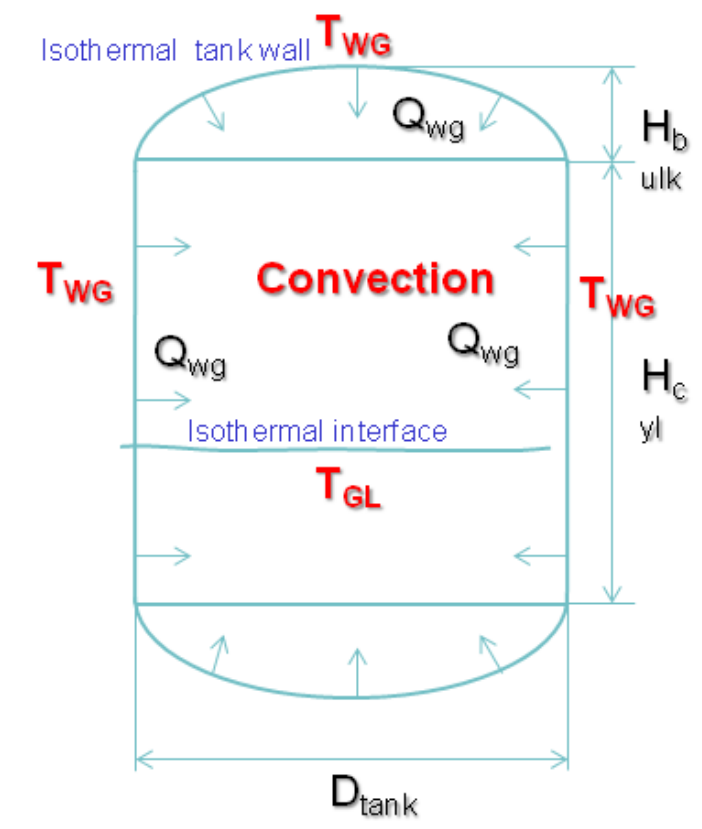

Figure 13: Model for steady solution of tank heat transfer problem.

The total heat transfer between the tank wall and the ullage gas can be expressed as:

$$
Q_{w g}=h_{w g} A_{w g}\left(T_{W G}-T_{G L}\right) .
$$

The total heat transfer from ullage to the gas-liquid interface is:

$$
Q_{g s}=h_{g s} A_{g s}\left(T_{W G}-T_{G L}\right) .
$$

At the steady state, the above two fluxes are equal, so one has the relationship of:

$$
h_{w g} A_{w g}=h_{g s} A_{g s} .
$$

Once heat transfer coefficient from the tank wall to ullage gas $\mathrm{h}_{\mathrm{wg}}$ is determined, the heat transfer from ullage gas to the gas-liquid interface can also be determined be as: 


$$
h_{g s}=\frac{A_{w g}}{A_{g s}} h_{w g} .
$$

A similar procedure can be applied to heat transfer coefficient between the tank wall and liquid phase $\mathrm{h}_{\mathrm{wl}}$ and that between the liquid phase and gas-liquid interface $\mathrm{h}_{\mathrm{ls}}$.

The extraction procedure is as follows:

1. Solve steady-state heat transfer problem with constant tank wall temperature ( $\left.\mathrm{T}_{\mathrm{WG}}\right)$ and constant gas-liquid surface temperature $\left(\mathrm{T}_{\mathrm{GL}}\right)$;

2. Compute local heat flux to the wall:

$$
q_{\text {wall }}=K_{\text {eff }} \frac{\partial T}{\partial n}
$$

3. Compute the mean heat transfer coefficient based on the total exposed tank surface area:

$$
\left.\bar{h}=\frac{\int q_{w a l l} d A}{\left(T_{W G}-T_{G L}\right) A_{w g}} ; \quad A_{w g}=\right\rfloor d A
$$

4. Define an equivalent total heat conduction flux based on a characteristic length $L$ and fluid conductivity $\mathrm{K}_{\mathrm{f}}$ as:

$$
Q_{\text {cond }}=K_{f} \frac{\left(T_{W G}-T_{G L}\right)}{L} A_{w g}
$$

5. Compute the non-dimensionalized Nusselt Number as

$$
N u=\frac{Q_{\text {convect }}}{Q_{\text {cond }}}=\frac{\bar{h} L}{K_{f}}
$$

6. Correlate Nusselt number as a function of Rayleigh number

Using the above approach, the natural convection in the gas phase and in the liquid phase can be separated. A generic tank with equal sized upper and lower domes is considered as illustrated in Figure 14. Here the barrel (cylindrical) section has a height of tank radius R. Three liquid level fill positions are considered: a) fill level to top of the barrel section, where the gas phase fills the upper dome (Figure 14a); b) fill level to the half-height of the barrel section, so that the liquid and gas phases have the equal volumes (Figure 14b); and c) fill level to the lower dome only, which is opposite to case a) (Figure 14c). The problem can now be separated into solving natural convection in the liquid, geometry corresponding to red color and natural convection in the gas phase with a gray colored geometry in Figure 14. 


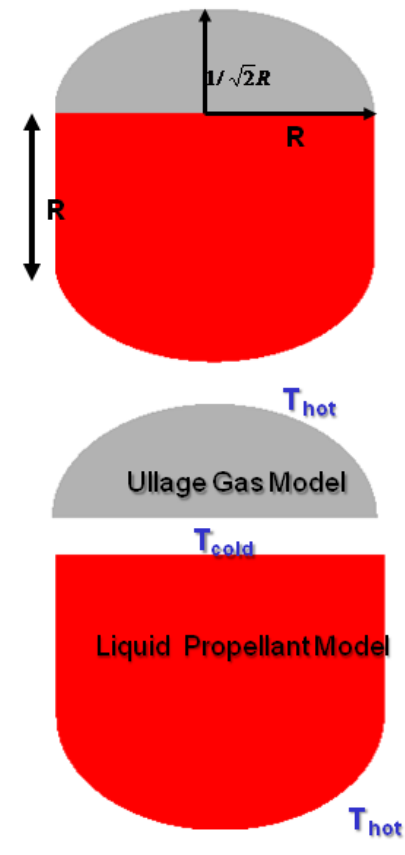

(a)

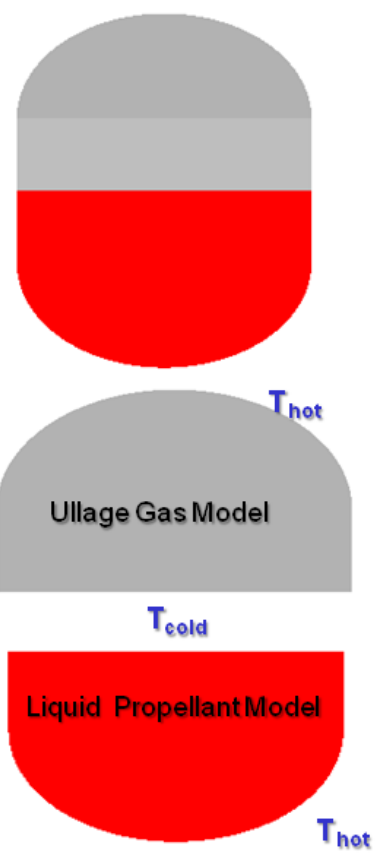

(b)
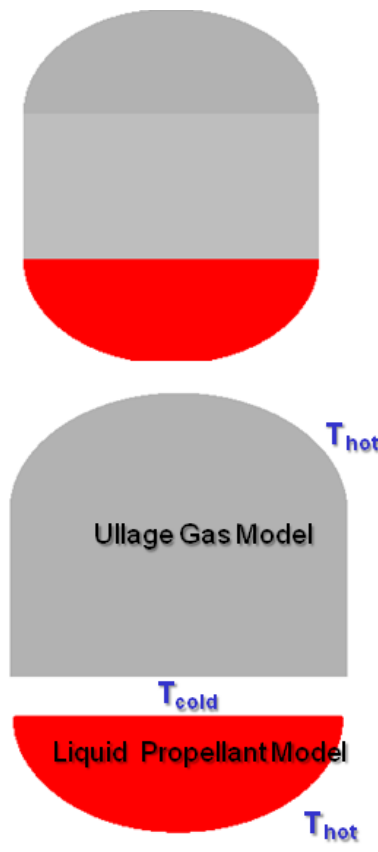

(c)

Figure 14: Three fill levels and models under consideration for natural convection inside a propellant tank.

\section{A. Simulation Model}

\section{Natural Convection of Liquid Propellant inside Tank}

The computational models for natural convection inside the liquid phase at the three fill levels shown in Figure 14 are given in Figure 15. The flow and temperature are assumed to be axis-symmetric so that a 2D model is sufficient. The grid is packed near wall with a total cell number varying from $28 \mathrm{~K}$ to $73 \mathrm{~K}$. A symmetry boundary condition is applied along the center axis. The gas-liquid interface is specified at a constant temperature of $21.46^{\circ} \mathrm{K}$, while the tank wall is at a constant temperature of $30^{\circ} \mathrm{K}$. The physical properties are assumed to be constant and are taken as the values at the reference temperature of $21.46^{\circ} \mathrm{K}$. The buoyancy force is applied in the momentum equation through the Boussinesq approximation, which implies that the density differences are sufficiently small to be neglected, except where they appear in the terms multiplied by g, the acceleration due to gravity.
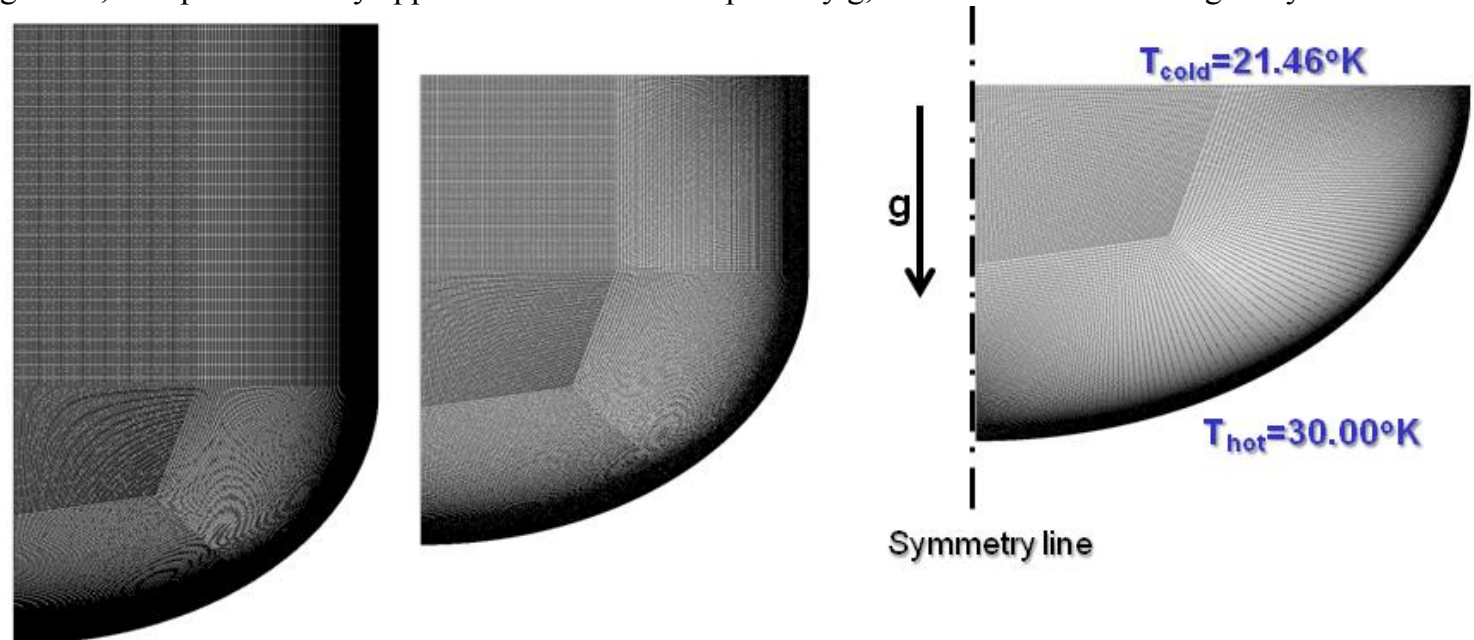

Symmetry line

Figure 15: CFD model for the liquid convection inside tank with different fill levels. 
The no-slip boundary condition is enforced on the gas-liquid interface as well as on the wall. In the reality, the gas-liquid interface satisfies a continuous shear stress condition along the interface which falls in between noslip and slip conditions. From that perspective, it will require the solution of both gas and liquid phases together. Since under steady state condition, the heat flux from tank wall to the liquid is the same as heat flux from liquid to the gas-liquid interface, the use of a no-slip boundary condition at interface will only affect the local temperature distribution. It has a small effect on the total heat flux, as we are more interested in the heat flux near the tank wall. For simplification, a no-slip condition at the interface is justified.

Table 2 lists the physical properties used in the simulation. As evident from Equation (10), many parameters can affect the value of Rayleigh number. For example, the characteristic length, L, which is typically the tank radius, the temperature differential $(\Delta \mathrm{T})$, fluid properties, and gravity condition $(\mathrm{g})$. Under different durations of a flight, the total acceleration can be very different, varying from $1 \mathrm{~g}$ on the ground to $4 \mathrm{~g}$ during the ascent of the flight, and to micro-g in space. In order to cover a wide of Rayleigh number, the gravity value is varied in the simulation.

Table 2. Liquid Properties under Consideration for the Natural Convectio
\begin{tabular}{c|c|} 
Property & Value \\
\hline Density, $\rho(\mathrm{kg} / \mathrm{m} 3)$ & 69.565 \\
\hline Viscosity, $\mu\left(\mathrm{kg} / \mathrm{m}^{*} \mathrm{~s}\right)$ & $1.2228 \times 10^{-5}$ \\
\hline Specific Heat, $\mathrm{Cp}(\mathrm{KJ} / \mathrm{kg} * \mathrm{~K})$ & 10.419 \\
\hline Thermal Conductivity, $\mathrm{K}(\mathrm{W} / \mathrm{m} * \mathrm{~K})$ & 0.10491 \\
\hline Thermal Expansion Coefficient, $\beta(1 / \mathrm{K})$ & 0.01754 \\
\hline Reference Temperature $(\mathrm{K})$ & 21.46 \\
\hline Gravity $\mathrm{g}\left(\mathrm{m} / \mathrm{s}^{2}\right)$ & $2.79 \times 10^{-9}$ to $9.8 \times 10^{2}$ \\
\hline
\end{tabular}

\section{B. Natural Convection for Liquid Filled to Lower Dome}

First we consider that case when the lower dome is filled with liquid, Case $\mathrm{c}$ of Figure 14. As Rayleigh number is a non-dimensional parameter, the Rayleigh number is allowed to vary from $10^{7}$ to $3.0 \times 10^{9}$ after scaling using the radius of these tanks. The temperature fields and streamlines for these tanks are given in Figure 16. At Rayleigh number of $10^{7}$, it is observed that a thermal boundary develops along the tank wall starting from the center line all the way to the gas-liquid interface. The fluid temperature increases by absorbing heat from the wall and the fluid flows up due to buoyancy to the gas-liquid interface. After hitting the cooler gas-liquid interface, the fluid gives up heat and is cooled while returning back along the center of the tank. Due to axisymmetry, the streamlines of natural convection are in the form of a torus. The thermal boundary layer becomes thinner with the increase of Rayleigh number for $\mathrm{Ra}=3 \times 10^{7}$ and $3 \times 10^{9}$. Based on the above study of a flat plate, two-layer turbulence model is applied when the Rayleigh number is above $10^{8}$. Numerical experiments show an independence of the solution on the use of turbulence model for Ra below $10^{8}$. Figure 17 displays the temperature fields and streamlines under even higher Rayleigh number. The thermal boundary layer is so thin that it is almost invisible. It should be noted that the grid is very fine near the tank wall, and there are at least 5 points inside the thermal boundary layer. In general the flow field is about the same showing a torus flow pattern.

The distribution of local heat flux based on Eq. (26) is plotted in Figure 18. A singularity is seen as the heat flux near the location where tank wall meets the gas-liquid interface. At the center line portion of the tank wall, a higher heat transfer is noticed due to the direct impingement of cold flow to the wall. The increase of thermal boundary thickness is observed from the temperature field, which leads to the reduction of heat flux until a sudden spike at the singularity point. 

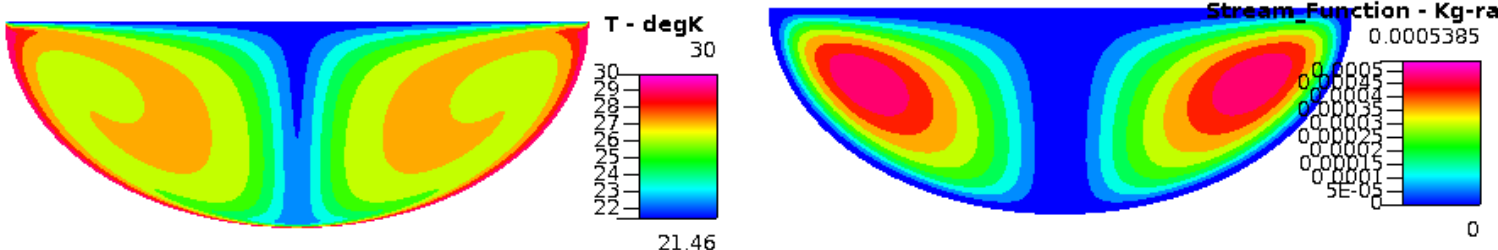

(a) $\mathrm{Ra}=10^{7}$, Laminar
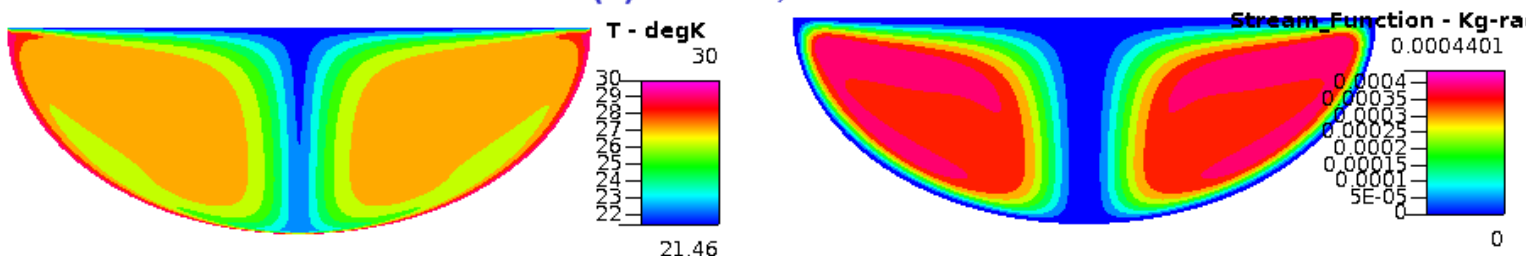

(b) $\mathrm{Ra}=3 \times 10^{7}$, Laminar
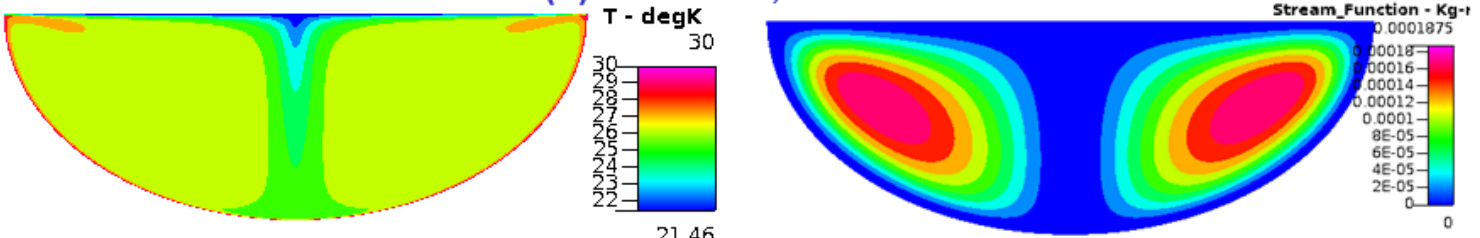

(c) $\mathrm{Ra}=3 \times 10^{9}$, Two Layer Turbulence Model

Figure 16: Temperature field and streamlines for natural convection inside liquid filled to the lower dome under laminar Rayleigh numbers.
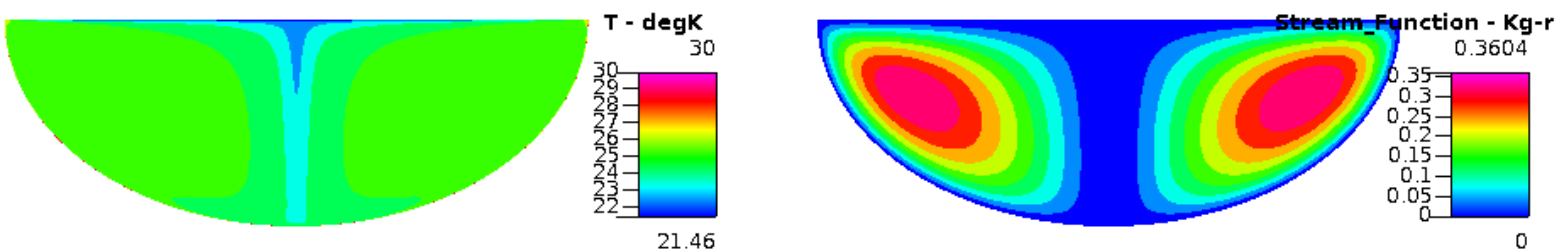

(a) $\mathrm{Ra}=1 \times 10^{13}$, Turbulence Model
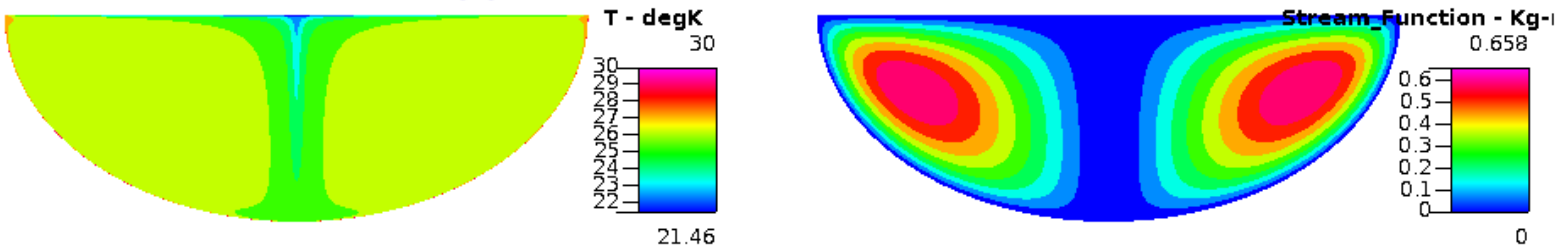

(b) $\mathrm{Ra}=3 \times 10^{13}$, Turbulence Model
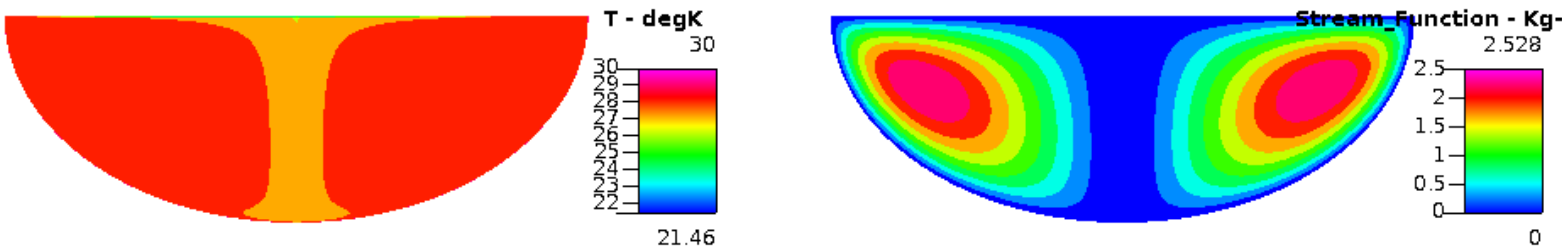

(c) $\mathrm{Ra}=10^{15}$, Turbulence Model

Figure 17: Temperature fields and streamlines for natural convection inside liquid filled to the lower dome at high Rayleigh numbers. 

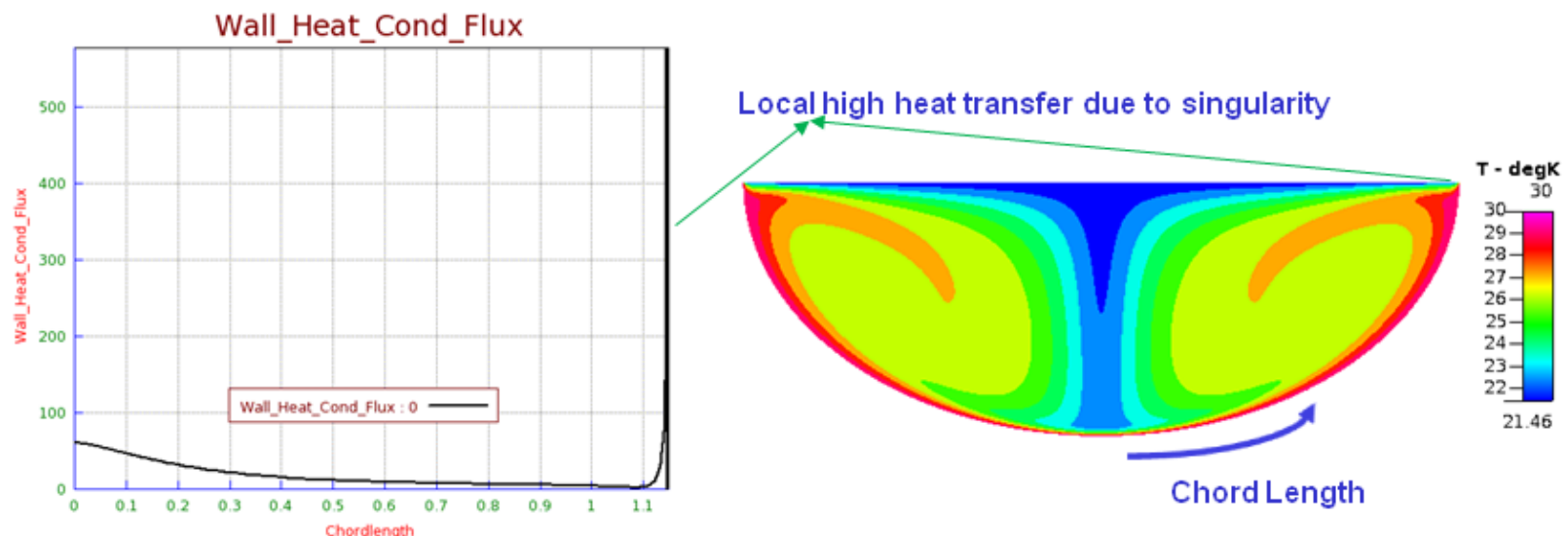

Figure 18: Distribution of local heat flux along the tank wall and the related temperature field.

With the computed heat flux, it is now possible to extract Nusselt number based on the procedure discussed earlier. As there is no direct length scale, the tank radius will be used in the calculation of Rayleigh and Nusselt numbers. The consolidated heat transfer rate is shown in Figure 19. The experimental correlation for the vertical plate under laminar and turbulent conditions and for the horizontal plate heated below are also shown in the same figure.

\section{Extracted Nusselt Number}

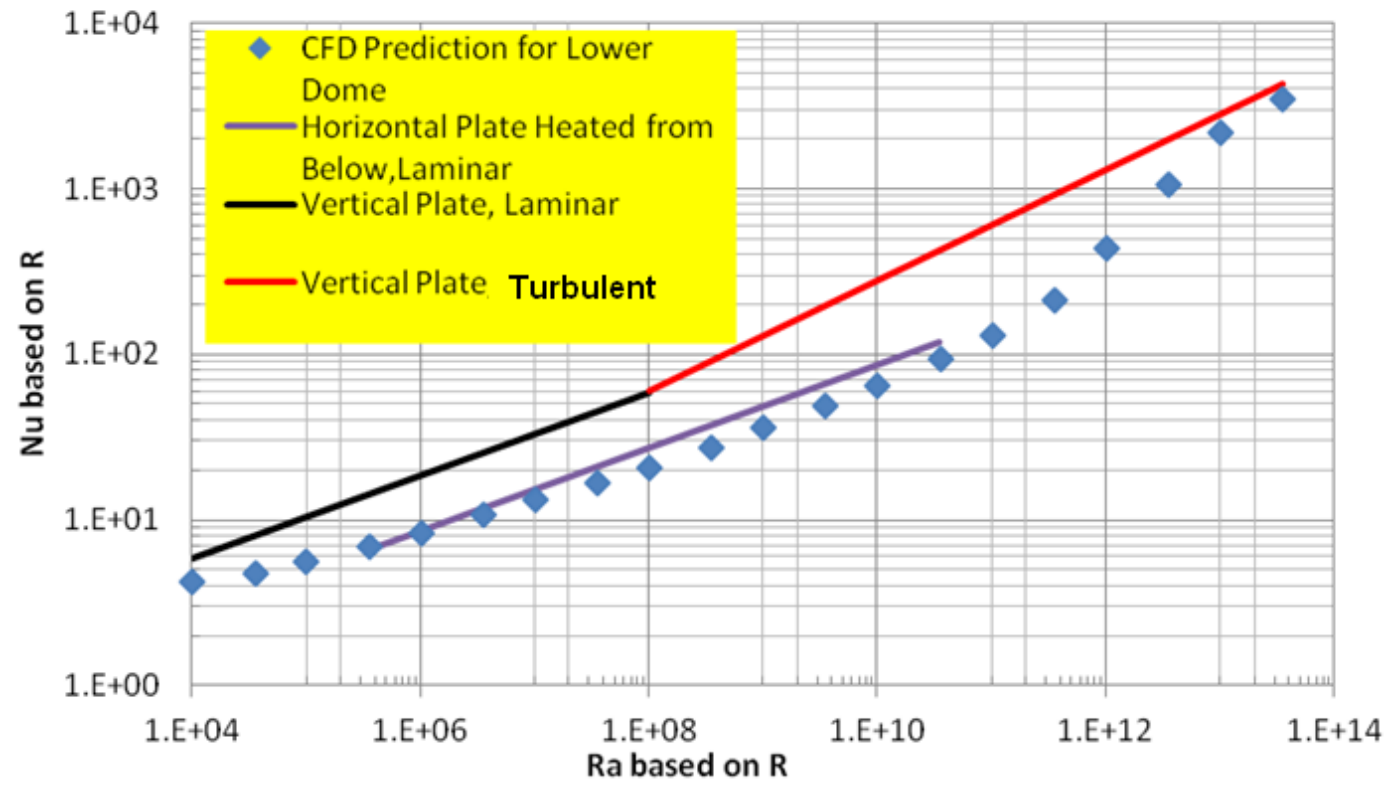

Figure 19: Nusselt number as a function of Rayleigh number for the lower dome filled with liquid.

It is observed that:

1. The application of the empirical curve correlated from vertically heated plate to a tank dome, as practiced in reduced order analysis, over-predicts heat transfer rate by as much as 5 times.

2. Empirical correlation for a surface heated from below fits the lower dome heat transfer characteristics very well. But the correlation is only available for laminar regime $\left(\mathrm{Ra}<3 \times 10^{10}\right)$.

3. CFD predictions are able to provide a reliable heat transfer coefficient for liquid propellant tank.

\section{Natural Convection for Liquid Filled to Half Barrel Height}

The Nusselt number based on the tank radius is plotted in Figure 20 at selected Rayleigh numbers, which are also based on tank radius. It is seen that the use of empirical correlations for either vertical plate or horizontal plate 
will over-predict heat transfer rate. The heat transfer rates from the present CFD predictions for the liquid fill levels at lower dome and at half radius height in barrel section don't collapse into a single curve using tank radius as the characteristic length.

\section{Extracted Nusselt Number}

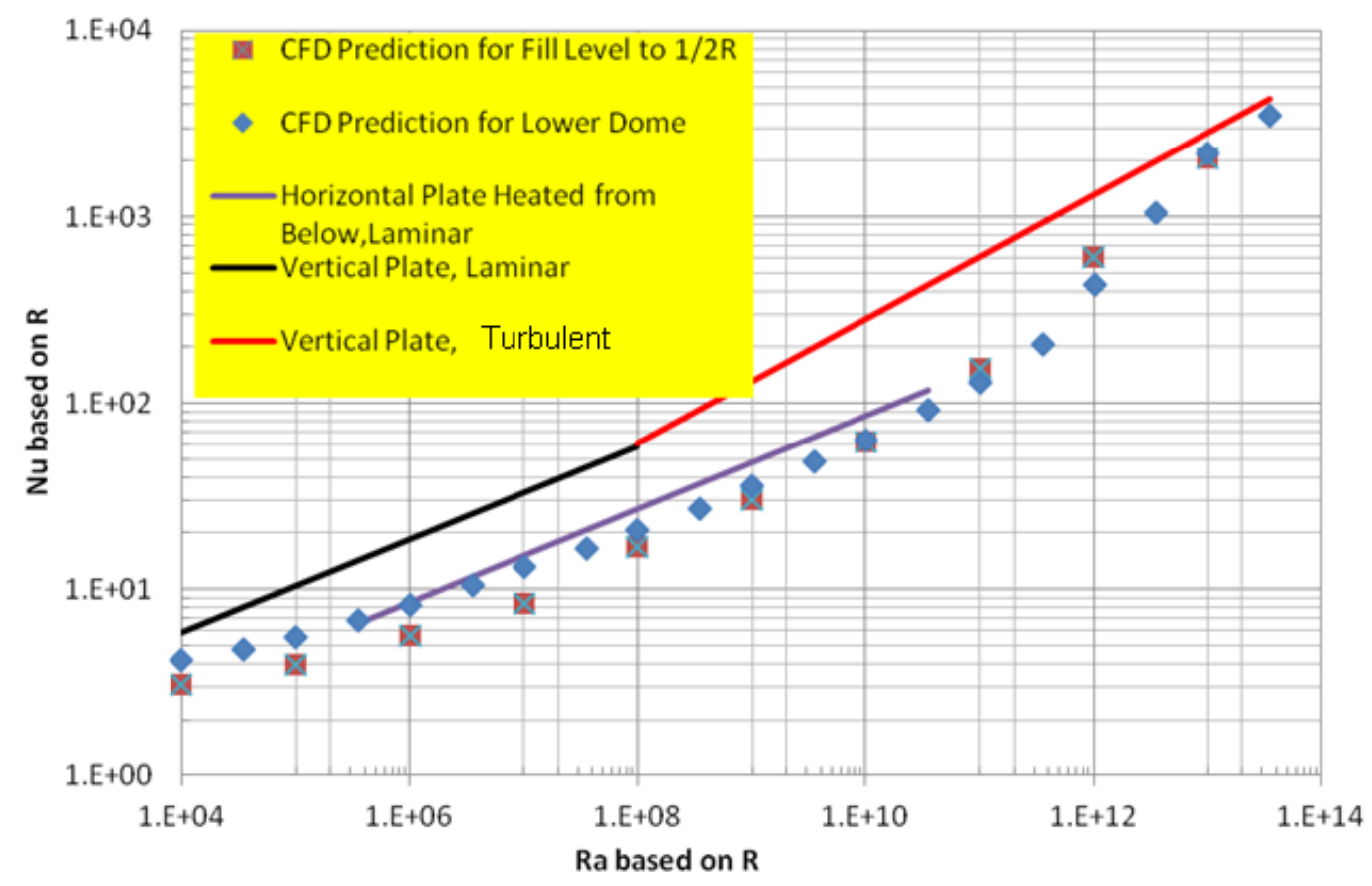

Figure 20: Nusselt number as a function of Rayleigh number for liquid level to $1 / 2 R$ in barrel section.

\section{Natural Convection for Liquid Filled to Full Barrel Height}

The Nusselt number based on the tank radius is plotted in Figure 21 at selected Rayleigh numbers, which are also based on tank radius as the length scale. It is seen that the use of empirical correlations for either vertical plate or horizontal plate tends to over-predict the heat transfer rate. Surprisingly, even under this condition with much more exposed vertical surface in the tank, heat transfer rate very much follows the trend of a horizontally heated plate rather than that of a vertically heated plate. One also notices that the CFD-predicted heat transfer rate for all three fill levels: up to lower dome, at half radius height and full radius height in barrel section, do not collapse into single curve using radius of tank as the characteristic length. 


\section{Extracted Nusselt Number}

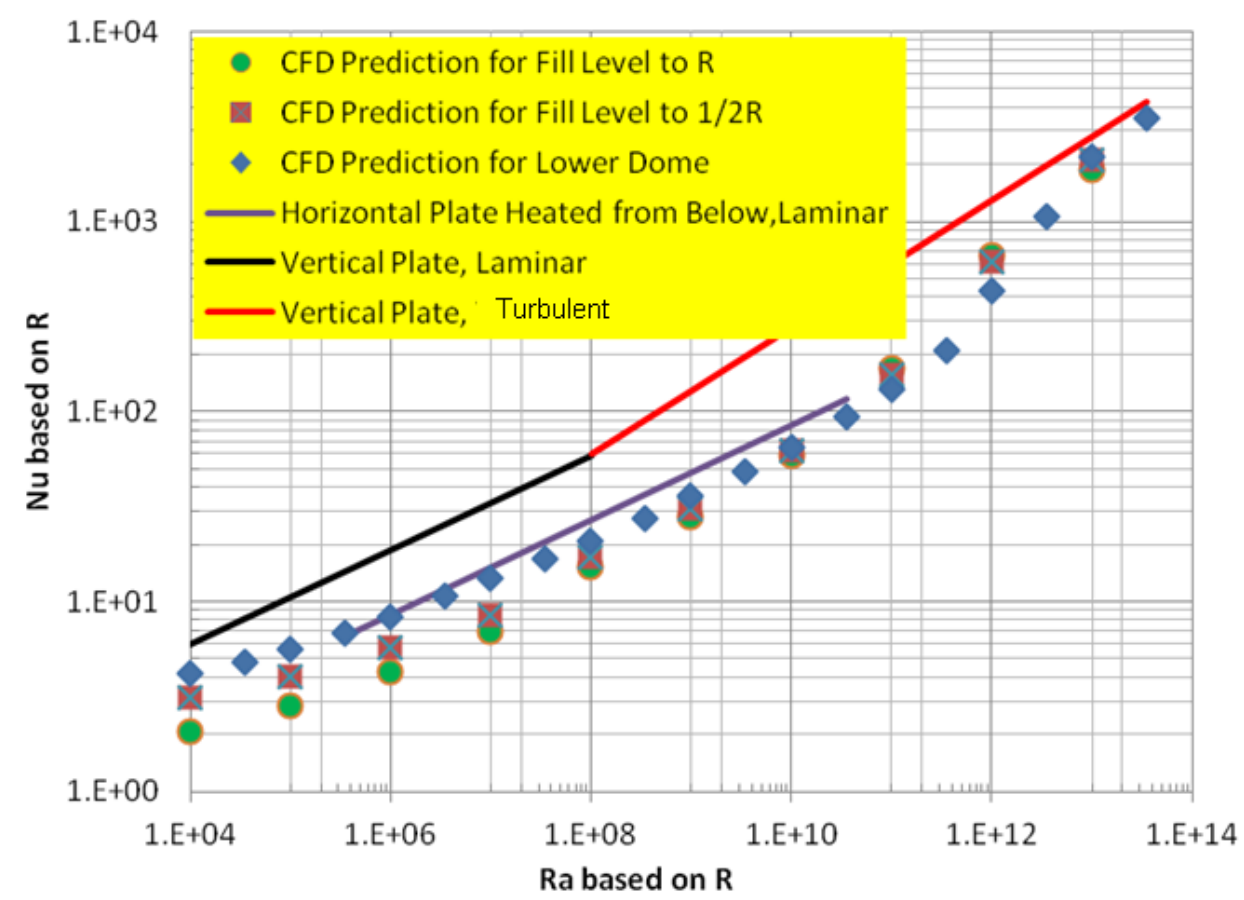

Figure 21: Nusselt number as a function of Rayleigh number for liquid level filled to a radius height in barrel section.

\section{E. Correlation Development for Natural Convection of Liquid Propellant inside Tank}

Based on the above study, we find that using the tank radius as the characteristic length, the resultant Nusselt number has different curves for different fill levels. Without a generalized correlation, it is difficult to apply the present results in engineering applications. The challenge is to find a characteristic length that will collapse the curves into a single correlation. In natural convection with a boundary layer, such as the case of flat plate, the vertical height is one of the important length scales. Here we propose a representative length scale for different fill levels as shown in Figure 22. This length scale is the wetted vertical height inside the tank. With this characteristic length, we have the following conversion for Nusselt and Rayleigh numbers:

$$
N u_{L}=\frac{L}{R} N u_{R}
$$

and

$$
R a_{L}=\left(\frac{L}{R}\right)^{3} R a_{R} .
$$

Using the above definition, the resultant Nusselt number, and Rayleigh number for different fill levels are plotted in Figure 23. It is clearly seen that all the data collapse into a single curve. This curve can be fitted into the following correlations: 

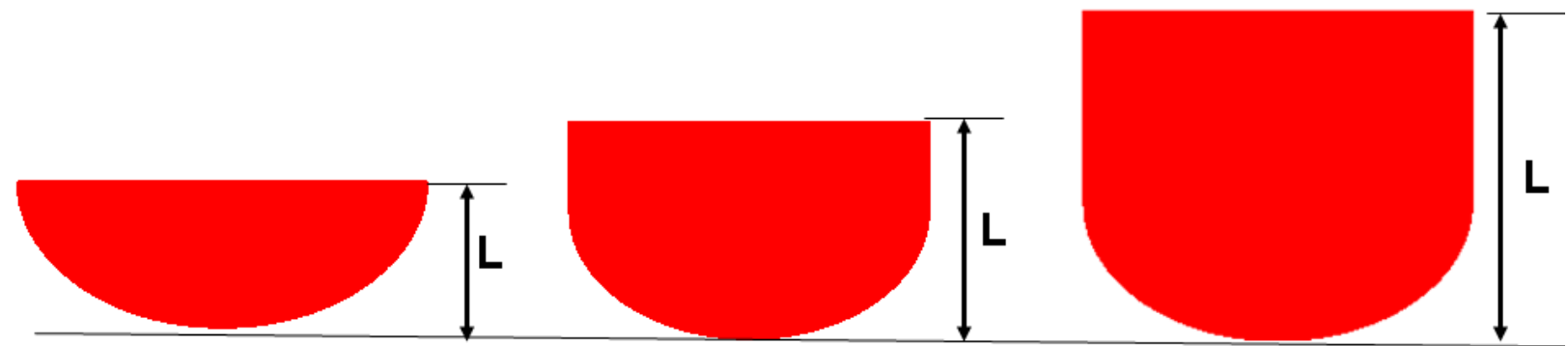

Figure 22: Representative length scale for different fill levels in the liquid tank.

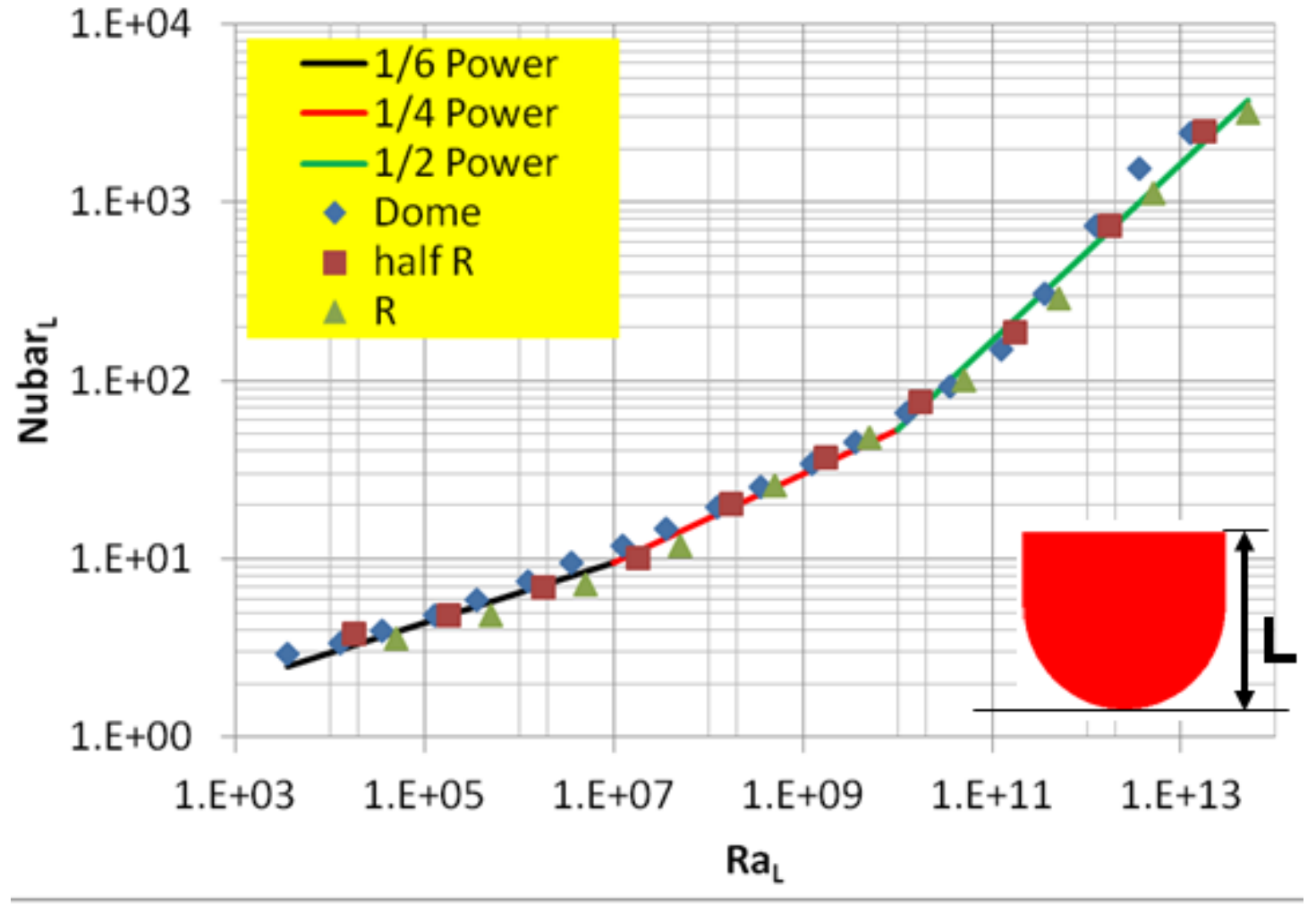

Figure 23: Curve fit using wetted liquid height as the characteristic length.

$$
\begin{array}{lc}
N u_{L}=0.642\left(R a_{L}\right)^{1 / 6} & R a_{L} \leq 10^{7} \\
N u_{L}=0.167\left(R a_{L}\right)^{1 / 4} & 10^{7}<R a_{L} \leq 10^{10} \\
N u_{L}=0.00053\left(R a_{L}\right)^{1 / 2} & 10^{10}<R a_{L} \leq 5 \times 10^{13}
\end{array}
$$

The above correlation is consistent with the previous study of a vertical flat plate in that in the laminar regime, the Nusselt number has a $1 / 4$ power to the Rayleigh number as predicted by analytical solution for laminar flow using similarity solution. In the turbulence regime, the Nusselt number grows faster inside the tank than that for the case of flat plate in an infinite medium. The current correlation displays a power of $1 / 2$ rather than $1 / 3$ with Rayleigh number. In the conduction regime for $\mathrm{Ra}<10^{7}$, it has a power of $1 / 6$.

The present correlation is compared with the previous experimental correlations for flat plate in Figure 24. One notices that the present curve trends closely with the heat transfer correlation for the horizontal plate geometry heated from below. However, the new correlation developed from this CFD study significantly increases the accuracy of heat transfer prediction and additionally shed light on the use of the liquid height as a viable characteristic length for non-dimensionalization. 


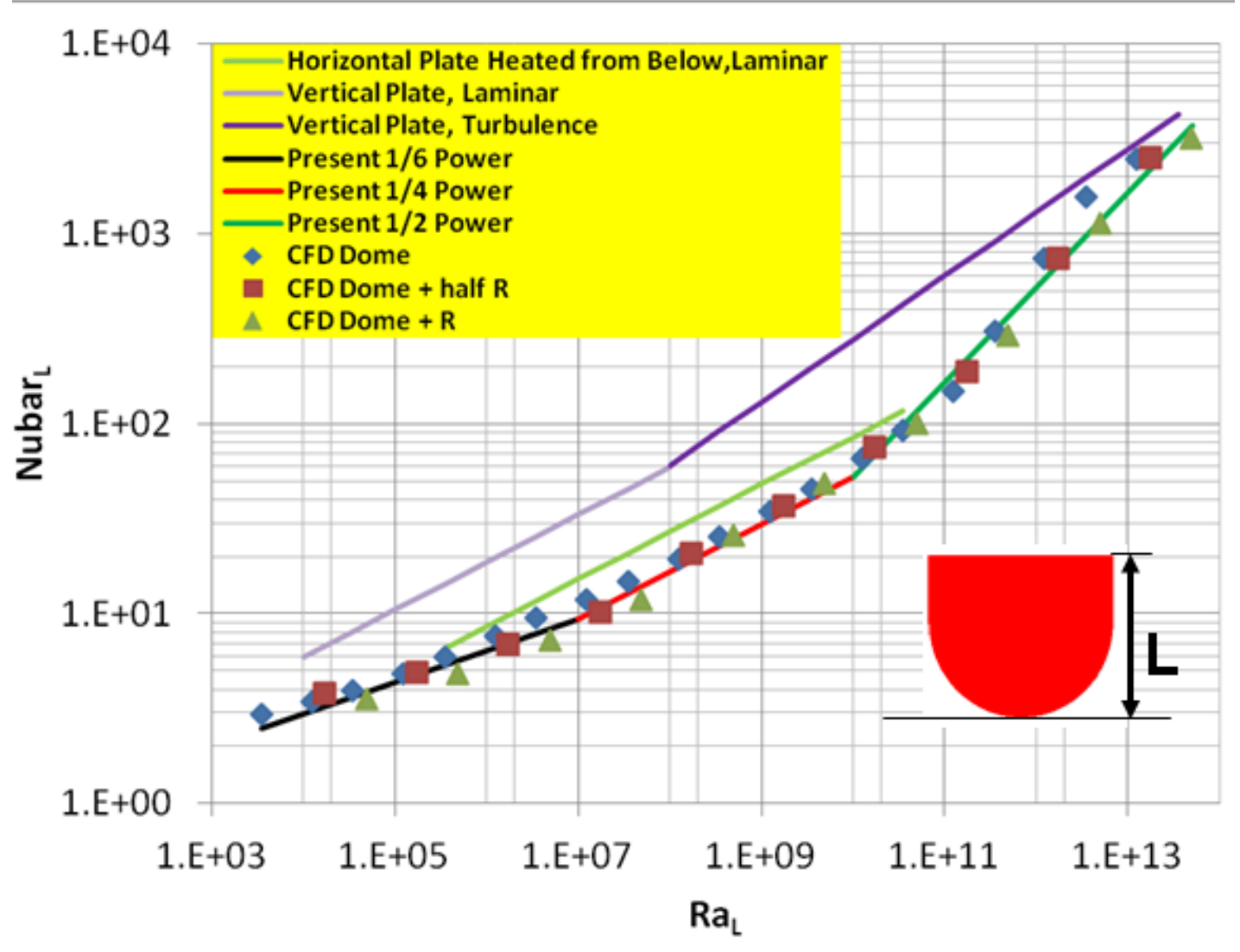

Figure 24: Present correlation for natural convection of liquid propellant inside a tank compared to that for heated flat plate.

\section{A. Simulation Model}

\section{Natural Convection of Ullage Gas inside Tank}

Next, we consider the natural convection of ullage gas above the gas-liquid interface. Here the tank wall is at a higher temperature and is above the gas-liquid interface as illustrated in Figure 14. By changing the gravity vector, the same three sets of grid for liquid phase can be used for the ullage gas phase. The computational model for the three fill levels is illustrated in Figure 25. The flow is assumed to be axisymmetric so that a $2 \mathrm{D}$ model is sufficient. The tank has the same size as the one used for liquid phase convection with a radius of 33.45 inches $(0.84693 \mathrm{~m})$. The grid is packed near the wall with a total cell number varying from $28 \mathrm{~K}$ to $73 \mathrm{~K}$. A symmetry boundary condition is applied along the center axis. The gas-liquid interface is specified at a constant temperature of $120^{\circ} \mathrm{K}$, while the tank wall is at a constant temperature of $140^{\circ} \mathrm{K}$. The gas-liquid interface temperature in the present gas phase convection is set at a different temperature from the case of the liquid phase convection. This is to reflect the fact that the ullage gas is typically stratified and has a higher temperature than that of the liquid. It is should be noted that under the assumption of constant physical properties and Boussinesq approximation, heat transfer rate is only a function of non-dimensional Rayleigh number. The selection of the above temperatures is from typical application encountered in cryogenic fluids. The physical properties are assumed to be constant and are taken at $130^{\circ} \mathrm{K}$. The buoyancy force is applied in the momentum equation through Boussinesq approximation. The no-slip boundary condition is enforced at gas-liquid interface as well as on the wall.

Table 3 lists the physical properties of ullage gas in the present simulations. It should be noted that to cover the whole range of Rayleigh number, from $10^{4}$ to $10^{12}$, the gravity value is different from that in the liquid case, as the gas physical properties are very much different from those of liquid. 
Table 3.Ullage Gas Properties under Consideration for the Natural Convection.

\begin{tabular}{|c|c|}
\hline Property & Value \\
\hline Density, $\rho(\mathrm{kg} / \mathrm{m} 3)$ & 0.50895 \\
\hline Viscosity, $\mu\left(\mathrm{kg} / \mathrm{m}^{*} \mathrm{~s}\right)$ & $1.138 \times 10^{-5}$ \\
\hline Specific Heat, $\mathrm{Cp}\left(\mathrm{KJ} / \mathrm{kg}^{*} \mathrm{~K}\right)$ & 0.5193 \\
\hline Thermal Conductivity, K $\left(\mathrm{W} / \mathrm{m}^{*} \mathrm{~K}\right)$ & 0.088 \\
\hline Thermal Expansion Coefficient $\beta(1 / \mathrm{K})$ & 0.01535 \\
\hline Reference Temperature $(\mathrm{K})$ & 130 \\
\hline Gravity $\mathrm{g}\left(\mathrm{m} / \mathrm{s}^{2}\right)$ & $7.9 \times 10^{-5}$ to $7.9 \times 10^{3}$ \\
\hline
\end{tabular}
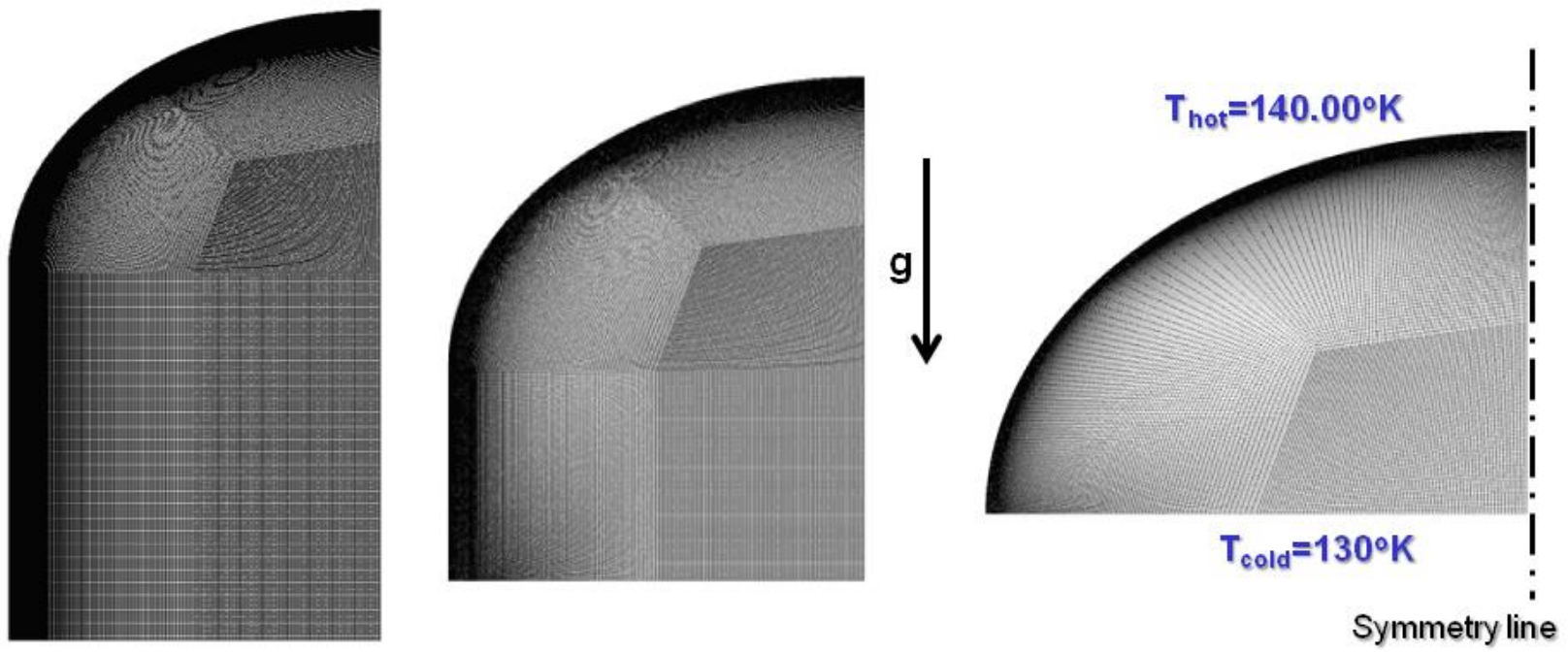

Figure 25: CFD model for the ullage gas convection inside tank with different liquid fill levels.

\section{B. Natural Convection of Ullage Gas}

First we consider the case when the liquid is filled to the bottom of the upper dome. The computational domain is simply an upper dome. At the bottom of the upper dome is the gas-liquid interface with a constant temperature of $130^{\circ} \mathrm{K}$. Along the tank wall, the temperature is fixed at a higher temperature of $140^{\circ} \mathrm{K}$. Figure 26 shows the temperature fields and streamlines for different Rayleigh numbers. At $\mathrm{Ra}=10^{4}$, the temperature field is stratified vertically with low convection current along the wall. As the heated tank wall is mainly situated on the top of the cold gas-liquid interface, the lighter fluid (hotter gas) is on the top of the heavier fluid (colder gas), so the convection is expected to be insignificant. That is indeed the case as one observes from the streamline distribution. The temperature field is essentially conduction dominated with convection arising near the dome-cylindrical section interface where the temperature gradient becomes normal to the gravity vector (unstable condition). One sees isothermal contours stratified except near the corner where tank wall meets the gas-liquid interface. As Ra increases to $10^{8}$, the temperature field is again stratified but with a higher gradient implying an increase in the total heat transfer. At Ra reaches a value of $10^{10}$ as shown in Figure 26(c), cells (similar to Benard cells) are visible from the streamlines. It is expected that heat transfer will be enhanced due to the convection of these small cells on the interface. 

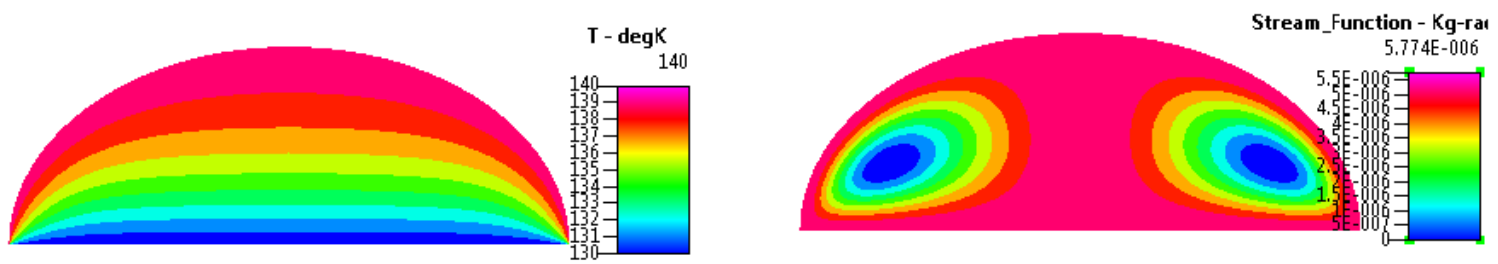

(a) $\mathrm{Ra}=10^{4}$, Laminar
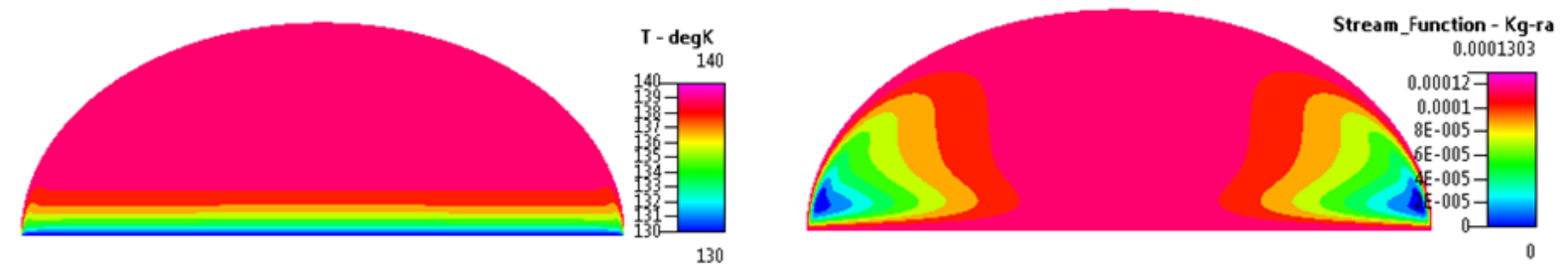

(b) $\mathrm{Ra}=10^{8}$, Laminar
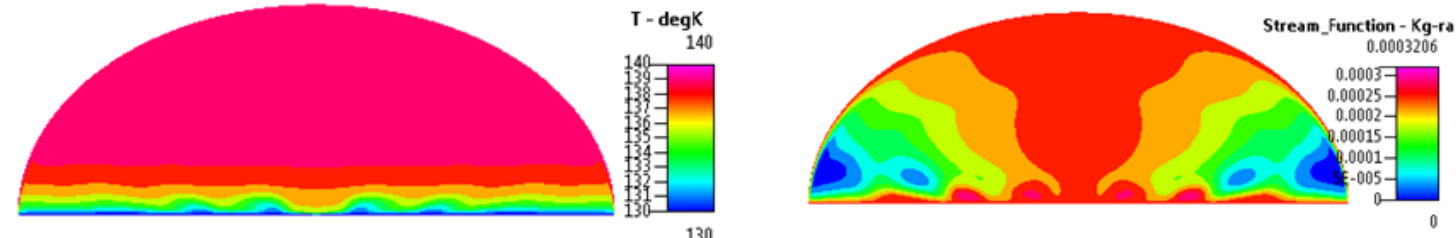

(c) $\mathrm{Ra}=10^{10}$, Turbulence Model

Bernard Cells

Figure 26: Temperature fields and streamlines for natural convection of ullage gas inside a tank with liquid filled to the bottom of the upper dome.

Figure 27 shows the temperature and flow fields for the liquid level filled to half and full radius heights. At $\mathrm{Ra}=10^{4}$, the temperature field is stratified and shows a conduction pattern. However, due to the difference in the barrel height, the heat transfer rate for the two cases is expected to be different.
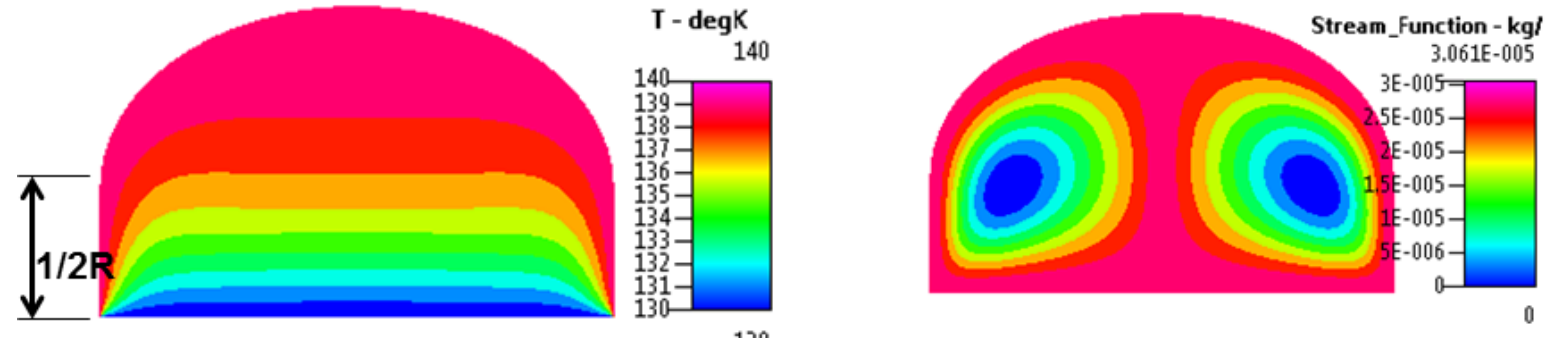

(a) $\mathrm{Ra}=10^{4}$, Laminar
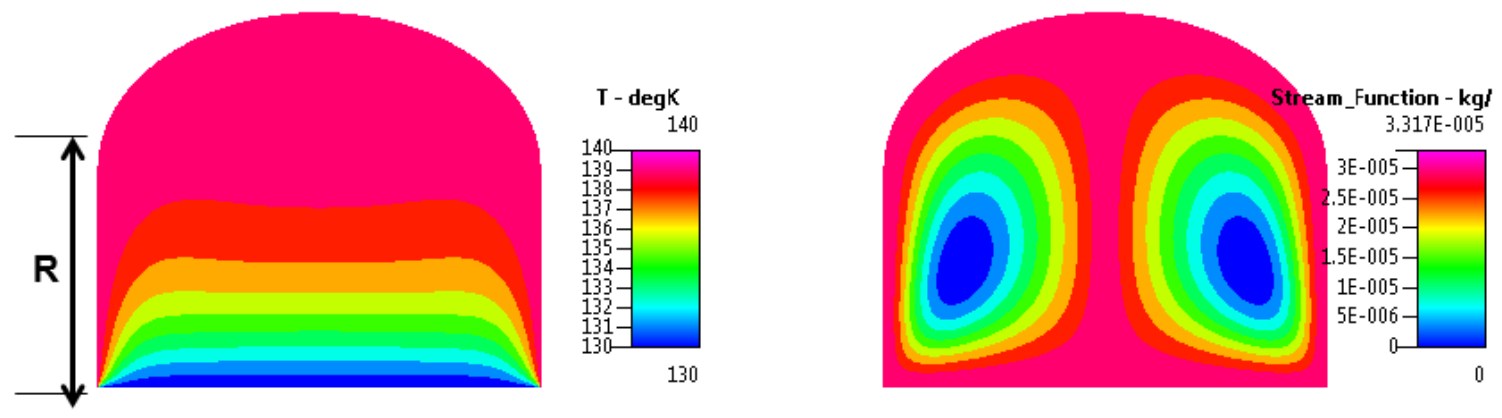

(b) $\mathrm{Ra}=10^{4}$, Laminar

Figure 27: Temperature fields and streamlines for natural convection of ullage gas inside a tank with liquid filled to half of radius height in barrel section. 


\section{Correlation Development for Natural Convection of Ullage Gas inside Tank}

The heat transfer coefficients are extracted from the above three liquid fill levels for the natural convection of the ullage gas. The Nusselt number based on the tank radius as a function of Rayleigh number is plotted in Figure 28. In general, one can see that for all the cases, heat transfer increases with Rayleigh number at a slow rate from low to intermediate Rayleigh numbers $\left(<10^{7}\right)$. This is consistent with the variation of temperature stratification seen from the plots in Figures 26-27. With the increase of Rayleigh number, the temperature gradient increases near the gas-liquid interface, but the convection effect is rather negligible. For $\mathrm{Ra}>10^{7}$, Benard-type cells start to develop near the interface, which leads to enhanced heat transfer. Just as for the case of liquid convection, the data are scattered, and there is no single correlation that can fit all the data.

In an attempt to find a characteristic length that can correlate all heat transfer rates at different fill levels into a simple curve, we choose the vertical height of the ullage gas volume. It measures from the gas-liquid interface to the top of the dome. It is consistent with the characteristic length for the liquid convection. The results are shown in Figure 29. Here indeed, data collapse into a single curve. Using this length scale, the Nusselt number is almost constant for the value of Ra less than $10^{7}$. This is very much heat conduction regime. For Ra from $10^{7}$ to $10^{12}$, Benard-type cells start to develop, and the curve follows a power of $1 / 4$, just as in the case of laminar heat transfer from a vertically heated plate using similarity solution. The general correlation can be expressed as:

$$
\begin{array}{rrr}
N u_{L} & =4.5 & R a_{L} \leq 10^{7} \\
N u_{L} & =0.08\left(R a_{L}\right)^{1 / 4} & 10^{7}<\mathrm{Ra}_{\mathrm{L}}<10^{12}
\end{array}
$$

Figure 29 also shows the comparison of the presently developed correlation to the commonly used correlations built from 1960's for vertically or horizontally heated flat plates. It is apparent that using the previous correlations can over-predict heat transfer rate by as much as one order of magnitude.

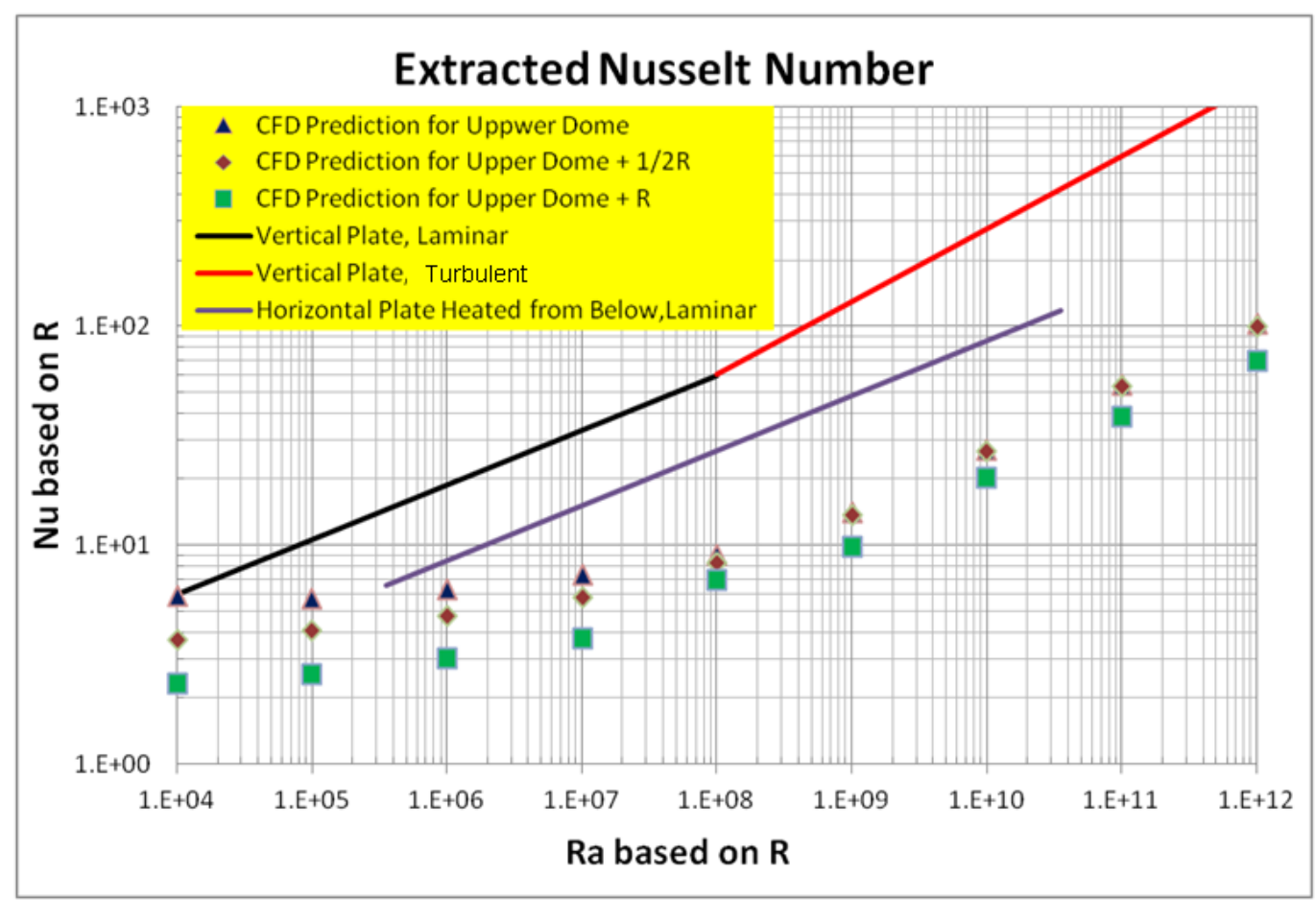

Figure 28: Predicted Nusselt number as a function of Rayleigh number with tank radius as the length scale and comparison to the correlation for either vertically heated plate or horizontally heated plate. 


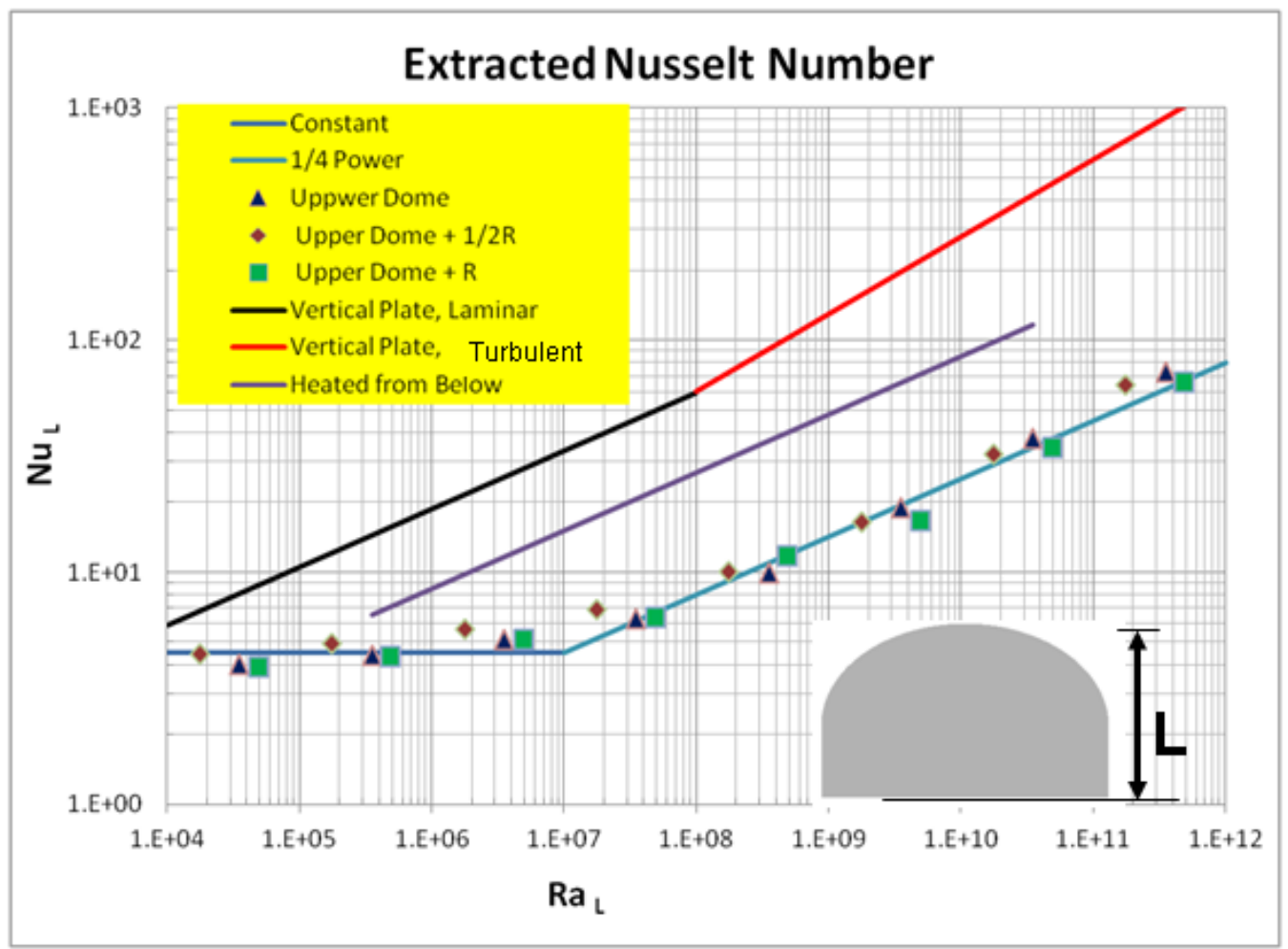

Figure 29: The present correlation for natural convection of ullage gas inside a propellant tank using the new characteristic length and comparison to that of heated flat plate.

\section{Conclusion}

A fundamental first principles based approach has been undertaken to improve understanding of heat transfer in cryogenic tanks. The CFD code, CFD-ACE+, was first validated against available experimental data and commonly used correlations for natural convection along a vertically heated wall. Good agreements between the present predictions and experimental data were found for flows in laminar as well as turbulent regimes.

With the validated CFD tool, the convective heat transfer between the tank wall and cryogenic propellant, and that between the tank wall and ullage gas have been simulated. In order to extract time independent heat transfer coefficient, the domain is divided into two parts, one for ullage, and one for liquid fluid.

The present study shows that commonly used heat transfer correlations for either vertical or horizontal plate will over-predict heat transfer rate by as much as one order of magnitude.

A characteristic length scale, defined as the wetted height $\mathrm{L}$, has been defined that can correlate all heat transfer coefficients for different fill levels into a single curve. This curve can be used for the reduced heat transfer model analysis.

In summary, the correlated heat transfer coefficient for the liquid propellant phase convection is:

$$
\begin{aligned}
& N u_{L}=0.642\left(R a_{L}\right)^{1 / 6} \\
& N u_{L}=0.167\left(R a_{L}\right)^{1 / 4} \\
& N u_{L}=0.00053\left(R a_{L}\right)^{1 / 2}
\end{aligned}
$$

$$
\begin{gathered}
R a_{L} \leq 10^{7} \\
10^{7}<R a_{L} \leq 10^{10} \\
10^{10}<R a_{L} \leq 5 \times 10^{13}
\end{gathered}
$$

For the ullage gas phase convection, it is:

$$
\begin{array}{lc}
N u_{L}=4.5 & R a_{L} \leq 10^{7} \\
N u_{L}=0.08\left(R a_{L}\right)^{1 / 4} & 10^{7}<\mathrm{Ra}_{\mathrm{L}}<10^{12}
\end{array}
$$




\section{Acknowledgements}

This study was performed under a Task Order ES.16.05.R42.SSEI.ISQ.0000 of the Jacobs Engineering NASA MSFC Contract NNM12AA41C. Dr. Ram Ramachandran was the Jacobs ESSSA Group Skill Lead, and Dr. Jeff West (MSFC Fluid Dynamics Branch, ER42) was the NASA MSFC Task Monitor. The assistance of Mr. Josh Rojahn, Jacobs ESTS in obtaining validation results is appreciated.

\section{References}

1. "Large Liquid Rocket Engine Transient Performance Simulation System, Final Report," United Technologies Corporation, Pratt \& Whitney, 1991, Contract Number NAS8-36994.

2. Ring, Elliot ed., Rocket Propellant and Pressurization Systems, Prentice-Hall Inc., Englewood Cliffs, NJ, 1964.

3. Mein, M. E. and Thompson, J. F., "Experimental and analytical Studies of Cryogenic Propellant Tank Pressurant Requirements", NASA TN D-3177, 1966.

4. Corpening, J. H., "Analytical Modeling of Pressurization and Cryogenic Propellant Conditions for Liquid Rocket-Based Vehicle designs", 2010.

5. Launder, B.E., and Spaulding, D.B., "The Numerical Computation of Turbulent Flows." Comp. Methods for Appl. Mech. Eng. 3(1974): 269-289.

6. Chen, H. C., and V. C. Patel., "Near-Wall Turbulence Models for Complex Flows Including Separation." AIAA Journal 26.6 (1988): 41-648.

7. Bejan, A. Convection Heat Transfer, John Wiley \& Sons, 1984. 